\title{
РОЖДАЕМОСТЬ В РАЗВИТЫХ СТРАНАХ: ОБЗОР ИССЛЕДОВАНИЙ
}

\author{
НИКОЛЕТТА БАЛЬБО, ФРАНЧЕСКО К. БИЛЛАРИ, МЕЛИНДА МИЛЛС
}

\begin{abstract}
Обзор исследований рождаемости в развитых обществах, т.е. обществах, в которых по умолчанию предполагается возможность контроля рождаемости. Главной целью статьи было представить всеобъемлющий обзор, который суммировал бы, как современные исследования объясняют текущие и прогнозируют будущие изменения рождаемости во времени и в пространстве (например, меж- $и$ внутристрановые различия). Следующая задача состояла в том, чтобы проанализировать детерминанты рождаемости, группируя их в пределах того уровня, на котором они действуют: 1) уровень индивида и/или семейной пары (микроуровень); 2) уровень социиальных связей и социальных сетей (мезоуровень); 3) уровень культурных и общественных институтов (макроуровень). В иентре намего внимания одновременно находится и уровень (quantum), и календарь (timing) рождаемости, особый акцент делается на откладывании деторождения. Обзор включает теоретические и эмпирические исследования с особым вниманием крезультатам тех из них, которые подтверждают или опровергают существующие теоретические предсказания. Внимание уделяется также проблемам определения причинно-следственных связей и эндогенности. В заключительной части статьи представлен контур основных проблем и возможностей для будущих исследований.
\end{abstract}

Ключевые слова: календарь (тайминг) рождаемости, откладывание рождений, уровень рождаемости, низкая рождаемость, детерминанты рождаемости.

\section{1. ВВЕДЕНИЕ}

Рождаемость была всегда центральной темой исследований в демографии, но в последние два десятилетия она вызвала значительный научный интерес со стороны других дисциплин: социологии, антропологии, экономики, медицины и психологии. За это время исследования рождаемости применительно к развитым обществам, в которых по умолчанию предполагается контроль над рождаемостью, буквально расцвели. Неудивительно поэтому, что уже было сделано несколько обзоров современной литературы о рождаемости [Hirschman 1994; Caldwell, Schindlmayr 2003; Sobotka 2004; Butler 2004; Morgan, Taylor 2006; Mills et al. 2011]. Эти обзоры представили основные существующие идеи с изложением возможных направлений дальнейших исследований (хотя иногда с упором на определенные дисциплины и географические ареалы). Начиная с 1980-х годов, росло число европейских и азиатских стран с очень низким уровнем рождаемости [Caldwell, Schindlmayr 2003], практически во всех развитых обществах наблюдалось «откладывание деторождения» [Kohler 2002a, b].

НИКОЛЕТТА БАЛЬБО (n.f.g.balbo@rug.nl), УНИВЕРСИТЕТ ГРОНИНГЕНА, НИДЕРЛАНДЫ.

ФРАНЧЕСКО К. БИЛЛАРИ, ОКСФОРДСКИЙ УНИВЕРСИТЕТ, ВЕЛИКОБРИТАНИЯ.

МЕЛИНДА МИЛЛС, УНИВЕРСИТЕТ ГРОНИНГЕНА, НИДЕРЛАНДЫ.

ПЕРЕВОД ОРИГИНАЛЬНОЙ СТАТЬИ ВАLВО N., F.C. BILLARI AND M.MILLS (2013). FERTILITY IN ADVANCED SOCIETIES: A REVIEW OF RESEARCH // EUROPEAN JOURNAL OF POPULATION. 29: 1. ПЕРЕВОД ВЫПОЛНЕН Е. ПЕТУХОВОЙ, Д. БОГОЯВЛЕНСКИМ И С. ЗАХАРОВЫМ. НАУЧНАЯ РЕДАКЦИЯ С. ЗАХАРОВА. URL: HTTP://LINK.SPRINGER.COM/ARTICLE/10.1007/S10680-O12-9277-Y 
По этой причине тема низкой рождаемости преобладала среди исследований в развитых странах. В конце 2000 -х годов разворот в динамике рождаемости в наиболее развитых странах, хотя и с большой неоднородностью трендов, привлек большое внимание [Goldstein et al. 2009; Myrskylä et al. 2009; OECD 2011]. Кроме того, влияние ситуации экономической неопределенности и недавнего экономического спада на рождаемость стали еще одной новой темой для изучения [Mills, Blossfeld 2005; Kreyenfeld 2010; Sobotka et al. 2011].

Центральный и всеобъемлющий вопрос данного обзора: каково состояние изучения рождаемости сегодня и куда оно движется? Чтобы ответить на этот вопрос, авторы обзора сначала классифицируют существующие исследования в соответствии с известными детерминантами рождаемости. Затем мы пытаемся выяснить, в какой степени мы можем использовать детерминанты рождаемости, описанные в существующих исследованиях, для объяснения текущих и ожидаемых изменений рождаемости во времени и в пространстве (т.е. меж- и внутристрановой неоднородности уровней рождаемости). Целью обзора также является аналитический синтез ключевых детерминант рождаемости и группировка их в пределах того аналитического уровня, где они действуют. Детерминанты, относящиеся к микроуровню, действуют на уровне индивида и/или семейной пары; относящиеся к мезоуровню охватывают социальные связи и социальные сети (например, характеристики связей с друзьями, коллегами, родственниками и/или к отношений, которые связывают их с данным лицом); относящиеся к макроуровню - культурные и общественные институты, в рамках которых протекает жизнь индивидов и семейных пар. Эта статья не только представляет современный обзор исследований и очерчивает структуру детерминант, но и расширяет наши знания, благодаря применению аналитической стратегии для категоризации этих детерминант с целью обеспечения лучшего понимания междисциплинарной и сложной задачи объяснения тенденций и различий в рождаемости.

Подобным же образом мы расширяем существующие обзоры, применяя более широкий междисциплинарный подход, который учитывает соответствующие вклады различных научных дисциплин помимо тех, что рассматривались ранее (чаще всего это были демография и социология). Мы также учитываем самые современные достижения в этой области, уделяя внимание недавнему перелому тенденции рождаемости в развитых обществах. Мы осознаем, что тема является очень обширной, так как существует множество определений термина «рождаемость» в различных дисциплинах. Область нашего рассмотрения не включает те исследования, в которых изучается не-человеческая рождаемость и даже не-животное размножение, рассматриваемые, главным образом, в биологической науке и науках об окружающей среде. Мы сосредоточиваемся только на рождаемости человека в развитых обществах и охватываем исследования, в первую очередь, относящиеся к таким дисциплинам, как демография, социология, медицина, биохимия, генетика, молекулярная биология, экономика и эконометрика, психология, теория принятия решений и здравоохранение.

В данной работе существующие исследования рождаемости рассматриваются систематически и комплексно, с выделением двух компонентов, которые характеризуют рождаемость: темn (“tетро”), т.е. календарь (“timing”) деторождения, и уровень (“quantum”), т.е. общее, итоговое число рожденных детей. При рассмотрении темпа 
деторождения мы учитываем, что в странах ОЭСР с 1970 г. наблюдался рост среднего возраста матери при рождении первого ребенка в сочетании с увеличением доли рождений у матерей старших возрастов, хотя и со значительной межстрановой вариацией [Billari et al. 2007; Sobotka et al. 2010; Mills et al. 2011]. Этот процесс, как правило, называют откладыванием деторождения, он занимает центральное место в исследованиях календаря рождаемости. Процесс перехода к рождению первого ребенка в более позднем возрасте (“postponement transition”) - главный феномен последних десятилетий [Kohler et al. 2002a, b; Billingsley 2010].

Уровень рождаемости связан с числом рожденных детей (с учетом бездетности). Согласно теории демографического перехода, уровень рождаемости должен был бы стабилизироваться на уровне простого воспроизводства населения - 2,1 ребенка на одну женщину [Bongaarts 2002]. В то же время в последние десятилетия XX века развитые страны демонстрируют низкий (“low”), сверхнизкий (“lowest-low”) и даже ультранизкий (“ultra-low”) уровень рождаемости, близкий к 1 [Kohler et al. 2002a, b; Frejka et al. 2010]. Новизна этого явления привлекла внимание демографов и вызвала озабоченность среди политиков по поводу долгосрочной демографической устойчивости их стран и растущего разрыва между желаемым и достигнутым уровнями рождаемости [Chesnais 1996; Bongaarts 2001; Goldstein et al. 2003; OECD 2011]. Однако исследования продемонстрировали, что фактический уровень рождаемости (т.е. число детей, рожденных к концу репродуктивного периода) был не таким низким, как показывал стандартный его измеритель - коэффициент суммарной рождаемости (КСР) [Bongaarts, Feeney 1998; Kohler et al. 2002a, b; Sobotka 2004]. Более того, в то время как, казалось бы, сложился консенсус по поводу того, что продвинутые общества будут либо оставаться на низком уровне рождаемости, либо достигнут еще более низкого уровня [Lutz et al. 2003], новые исследования свидетельствуют о начале разворота в тенденциях рождаемости в 2000-х годах [Goldstein et al. 2009; Myrskylä et al. 2009; OECD 2011].

Откладывание рождений тесно связано с уровнем рождаемости, так как возраст матери при рождении первого ребенка влияет на (итоговое) общее число детей. Календарь рождений всегда сильно влиял на уровень рождаемости, который обычно является объектом измерений, в то время как некоторые измерители, используемые для изучения уровня рождаемости, не зависят исключительно от календаря рождаемости. Наиболее известный пример - коэффициент суммарной рождаемости (КСР). Даже на микроуровне существует воздействие календаря рождений на итоговое число рождений, так как «отсрочка» рождений или ранние (возможно, незапланированные) роды могут каким-то образом повлиять на общее число детей. Это особенно актуально при изучении вероятности рождения очередного ребенка в течение некоторого интервала времени (набирающая популярность тема в последнее время). По этим причинам мы также акцентируем внимание на взаимосвязи между темпом и уровнем рождаемости.

Продолжение статьи структурировано следующим образом. Раздел 2 посвящен детерминантам рождаемости на микроуровне, затем следует 3-й раздел, в котором представлены исследования факторов, действующих на мезоуровне. Раздел 4 содержит обзор исследований рождаемости на макроуровне. В заключении мы рассматриваем современные проблемы и возможности для будущих исследований рождаемости. 


\section{2. ДЕТЕРМИНАНТЫ РОЖДАЕМОСТИ, ДЕЙСТВУЮЩИЕ НА МИКРОУРОВНЕ}

Исследования на микроуровне фокусируются на процессе принятия решений, осуществляемых индивидуумом и/или семейной парой, которые лежат в основе выбора иметь ребенка, и на изучении обстоятельств, влияющих на решения относительно сроков и числа детей. Выбор часто характеризуется как рациональный ответ на неопределенность и/или как следование предписанной последовательности жизненных событий. Большое количество исследований посвящено связи между обстоятельствами и траекториями жизненного пути (главным образом, брачно-семейным партнерством, образованием, занятостью и экономическими условиями) и репродуктивным поведением. Другие исследования фокусируются на роли социального класса, семьи и происхождения в целом, которые, в свою очередь, формируют ценности и предпочтения человека. Основная трудность на этом направлении исследований заключается в сложности установления причинно-следственной связи (“causality”) или, другими словами, в возможности эмпирически определить, являются ли данные жизненные обстоятельства реальными детерминантами рождаемости или на эти обстоятельства жизненного пути и на репродуктивное поведение одновременно влияют общие детерминанты (эндогенность или обратная причинность).

\section{1. Роль намерений в процессе принятия репродуктивных решений}

Многие исследователи рассматривали репродуктивные намерения в качестве промежуточных детерминант фактического репродуктивного поведения, изучая конкретные факторы, влияющие на формирование, реализацию и/или изменения этих намерений [Westoff, Ryder 1977; Schoen et al. 1999; Quesnel-Vallée, Morgan 2003; Berrington 2004; Liefbroer 2009; Philipov 2009; Spéder, Kapita'ny 2009; Morgan, Rackin 2010; Iacovou, Tavares 2011]. Другие видели в систематическом разрыве между ожидаемой и фактической рождаемостью одну из причин низкой рождаемости [Morgan, 2006], так как этот разрыв свидетельствовал о «неудовлетворенной потребности» в детях [Liefbroer 2009].

Шпедер и Капитани [Spéder, Kapitany 2009] приводят подробный обзор широкой дискуссии по поводу способности репродуктивных намерений служить предиктором реального поведения. Наряду с критическими работами, ставящими под сомнение высокую объяснительную силу репродуктивных намерений и таких менее индивидуализированных измерителей, как идеальный размер семьи [Westoff, Ryder 1977; Quesnel-Vallée, Morgan 2003], имеются исследования, в которых утверждается, что намерения являются эффективными предикторами фактической рождаемости [Schoen et al. 1999; Berrington 2004]. Большинство последних исследований на эту тему опирается на социальнопсихологическую литературу, часто использующую теорию запланированного поведения (ТЗП) (“theory of planned behavior"/ ТРВ) [Ajzen 1991]. Данную теорию, помимо других подходов, эксплицитно адаптировали Биллари с соавторами [Billari et al. 2009] в своем исследовании по Болгарии, а также Доммермут с соавторами [Dommermuth et al. 2009], занимавшиеся этой темой в Норвегии. Кроме того, эта теория использовалась при разработке вопросника в международной программе сравнительных исследований «Поколения и гендер» [Vikat et al. 2007]. Согласно теории запланированного поведения, намерения - это уникальное сочетание трех предпосылок: 1) установок (т.е. восприятие 
индивидом затрат и выигрышей при том или ином поведении); 2) субъективных норм (например, влияние близких друзей и родственников); 3) воспринимаемого контроля над собственным поведением (т.е. той степени, в которой поведение воспринимается как объект контроля со стороны индивида).

Используя другой социально-психологический подход, Миллер и Паста [Miller, Pasta 1994, 1995] адаптируют концепцию «мотивационные диспозиции - желания намерения - поведение» ("traits-desires-intentions-behavior"/ TDIB), в которой репродуктивные намерения встроены в сложную структуру принятия решений. Миллер [Miller 2011] утверждает, что рождение ребенка является результатом последовательности стабильных мотивационных диспозиций, которые преобразуются в желания, а те в свою очередь формируют репродуктивные намерения. Эти намерения затем трансформируются в определенное поведение, направленное на избегание беременности или на ее реализацию. Альтернативная модель для объяснения рождаемости - теория конъюнктурных действий ("theory of conjunctural action"/ TCA), недавно представленная Морганом и Бахрахом [Morgan, Bachrach 2011]. В соответствии с этой теорией репродуктивное поведение является результатом взаимодействия между уникальным набором социальных условий (например, нормативных ожиданий и структурных факторов) и схемами, представляющими собой структуры человеческого сознания, которые используются мозгом для восприятия окружающего мира и обработки информации. Данная теория отличается от теории запланированного действия утверждением, что репродуктивное поведение может быть не только результатом обоснованного, рационального целеполагания, но и результатом автоматического, неосознаваемого процесса.

В существующей литературе рассматриваются два основных типа репродуктивных намерений: 1) количественные намерения (т.е. желаемый размер семьи); 2) намерения в отношении очередного ребенка (т.е. намерения иметь (еще одного) ребенка вообще или в течение какого-то определенного времени). Было показано, что количественные намерения оказываются довольно слабым предиктором общего фактически имеющегося или реализованного числа детей [Quesnel-Vallée, Morgan 2003], поскольку намерения в отношении числа детей могут меняться в сторону увеличения или уменьшения в течение жизни [Liefbroer 2009; Iacovou, Tavares 2011]. Основными факторами, вызывающими изменения в репродуктивных намерениях, являются ожидания со стороны партнера [Iacovou, Tavares 2011], изменения брачно-партнерского статуса, вид деятельности и предшествующие репродуктивные события [Liefbroer 2009]. Намерения в отношении очередного рождения рассматриваются как более стабильные и надежные [Schoen et al. 1999; Philipov 2009], несмотря на то, что некоторые исследования показали несоответствие между намерениями и реальным поведением [Westoff, Ryder 1977; Toulemon, Testa 2005]. Указание сроков (например, 2 или 3 года) значительно улучшает прогностическую ценность репродуктивных намерений [Billari et al. 2009; Philipov 2009].

\section{2. Партнер и брачно-партнерские отночения}

Произошедшие изменения в динамике брачно-партнерских союзов, наблюдаемые в последние десятилетия в развитых обществах, связываются с отсрочкой родительства. Растущее число исследований показывает параллельную тенденцию откладывания 
формирования союзов и родительства [Corijn, Klijzing 2001; Mills et al. 2005], увеличения количества партнеров до рождения первого ребенка [Wu, Schimmele 2005], роста незарегистрированных сожительств, которые связывают с более поздним возрастом вступления в брак [Bumpass et al. 1991; Mills 2004], если не с «отходом от брака» вообще [Gibson-Davis et al. 2005].

Репродуктивные намерения партнера также играют важную роль в реализации намерений индивида, так как решение родить ребенка в развитых обществах пара принимает сообща. Если в паре существуют разногласия по поводу ожидаемого рождения ребенка, то шансы реализации положительных репродуктивных намерений одного из партнеров уменьшаются [Thomson 1997, 2002; Schoen et al. 1999]. Брачно-партнерский статус также является сильным предиктором, и если отношения партнеров нестабильны, рождение ребенка менее вероятно [Hobcraft, Kiernan 1995; Philipov et al. 2006; Testa 2006]. Отмечается также ослабление связи первого рождения с браком [Buchmann, Kriesi 2011], что ассоциируется с тенденцией роста внебрачных рождений [Dalla Zuanna 2001; Billari, Kohler 2004]. Хотя было показано, что риск иметь первого ребенка во внебрачном союзе ниже, чем в брачном [Brien et al. 1999; Baizán et al. 2003, 2004; Spedér, Kapitány 2009], роль сожительства и его взаимосвязь с деторождением в сравнении с браком различаются по странам [Heuveline, Timberlake 2004]. Во Франции вероятность рождения ребенка у партнеров, проживающих в неформальном союзе, и у брачных пар примерно одинакова [Toulemon, Testa 2005], тогда как в США сожительство связано с меньшей вероятностью деторождения [Heaton et al. 1999]. Помимо желания иметь ребенка, обнаруживается множество иных характеристик партнеров или супружеских пар, которые также влияют на рождение детей [Thomson et al. 1990; Corijn et al. 1996; Thomson, Hoem 1998; Jansen, Liefbroer 2006].

С ростом числа нестабильных союзов, сепараций и разводов еще одной актуальной темой стала оценка влияния на деторождение стабильности/нестабильности союза и/или низкого качества партнерских отношений. Хотя причинно-следственные связи весьма сложны и имеются важные механизмы обратной связи [Waite, Lillard 1991], в существующей литературе отмечаются два противоположных механизма. С одной стороны, некоторые исследования обнаруживают отрицательную связь между низким качеством/нестабильностью партнерства и рождением детей [Thornton 1978; Myers 1997]. Пары, для которых характерна неустойчивость в отношениях, имеют меньше шансов родить ребенка за счет уменьшения частоты половых контактов [Cohen, Sweet 1974; Thornton 1977, 1978] или потому что они считают, что дети могут усложнить прекращение их союза [Lillard, Waite 1993]. С другой стороны, Фридман и соавторы [Friedman et al. 1994] утверждают, что нестабильный союз приводит к более раннему деторождению, так как дети рассматриваются как фактор уменьшения неопределенности и способ повышения брачной солидарности. Этот последний аргумент был подтвержден дополнительными эмпирическими исследованиями [Wu 1996; Myers 1997]. Райкен и Томсон [Rijken, Thomson 2011] показали, что существует нелинейная связь между качеством брачных отношений и рождаемостью: женщины, у которых качество отношения с партнером находится на среднем уровне, более склонны родить одного (еще одного) ребенка, потому что они в большей степени хотят сохранить отношения. Райкен и Лифброер [Rijken, Liefbroer 2009] 
исследовали также влияние качества партнерства на календарь рождений. В очередной раз были выделены два альтернативных механизма: в одном случае, высокое качество отношений создает «благоприятную среду» для воспитания детей; в другом, рождение ребенка может рассматриваться как средство «оживления» отношений между партнерами.

\section{3. Гендерное разделение труда}

Еще один важный фактор, влияющий на рождаемость, - гендерное разделение труда между партнерами в домохозяйстве. Современные исследования в этой области основываются на гендерной теории рождаемости П. Макдональда [McDonald 2000a, b], которая утверждает, что очень низкая рождаемость - это результат сохранения устойчивого гендерного неравенства в семейно-ориентированных социальных институтах. Для Эспинг-Андерсена [Esping-Andersen 2009], опирающегося на работу экономиста Голдина [Goldin 2006], низкая рождаемость - это следствие «незавершенной» революции, которая трансформировала женские роли. Эмпирические исследования, рассматривающие гендерное равенство на микроуровне, предоставляют интересные подробности о том, как гендерная роль в семье влияет на вероятность для индивида иметь ребенка. В качественном исследовании рождаемости женщин в Канаде Мэттьюс [Matthews 1999] приходит к выводу, что женщины, чувствующие себя перегруженными домашней работой, имеют меньше детей, чем другие. Используя данные по США, Миллер Шорт и Topp [Torr 2004] обнаружили U-образную зависимость между гендерным равенством в паре и рождаемостью: вероятность рождения второго ребенка выше в семьях с очень низкой или очень высокой степенью гендерного равенства. Тази-Преве и соавторы [Tazi-Preve et al. 2004] считают, что неравномерное распределение домашнего труда снизило репродуктивные намерения у мужчин в Австрии. Эта мысль поддерживается в работе Ола [Oláh 2003], который, сравнивая Швецию и Венгрию, обнаружил, что более равное гендерное распределение домашних обязанностей в семье ускоряет принятие решения о рождении второго ребенка, отметив, что специальная политика в Швеции также способствовала этому. Кук [Cooke 2009] в своем исследовании ситуации в Италии и Испании отмечает, что повышение равенства в уровне занятости партнеров способствует увеличению равенства в разделения домашнего труда, что положительно влияет на вероятность рождения второго ребенка. Однако это влияние было неодинаковым в сравниваемых странах. Исходя из результатов сравнительного исследования Нидерландов и Италии, Миллс и соавторы [Mills et al. 2008] утверждают, что неравное разделение домашнего труда существенно влияет на репродуктивные намерения у женщин в случае, когда у них уже имеется тяжелая нагрузка (больше рабочих часов, дети), что особенно характерно для работающих женщин в Италии. Бегалл и Миллс [Begall, Mills 2011] также показали, что степень конфликта между работой и семьей играет важную роль для женщин во многих европейских странах, в которых преобладает неполный рабочий день и существует более строгий контроль выполняемой работы, что значительно влияет на намерения стать матерью.

\section{4. Рождаемость в повторных союзах}

Увеличение распространенности нестабильных и многократных союзов привело к росту исследований о рождаемости в повторных союзах. Эти исследования показывают, что партнеры, которые уже имеют детей от предыдущих союзов, с большей вероятностью хотят 
общего ребенка, что выглядит как эффект совместных обязательств [Vikat et al. 1999; Buber, Prskawetz 2000; Stewart 2002; Thomson 2002; Prskawetz et al. 2003]. Джеффрис и соавторы [Jefferies et al. 2000], например, нашли, что среди британских женщин почти половина тех, кто имел опыт развода, впоследствии беременеют в течение двенадцати месяцев, при этом возраст женщины и возраст ее младшего ребенка являются наиболее важными факторами наряду с вступлением в новый союз. Следовательно, повторный брачно-партнерский союз может подпитывать более высокий уровень рождаемости. Учитывая, что одного ребенка достаточно для свидетельства выполнения брачных обязательств, многократные отношения и последующие партнерства могут вносить значительный вклад в суммарную рождаемость.

\section{5. Доход, образование и человеческий капитал}

Социально-экономические условия жизни индивида также изучаются как детерминанты уровня и календаря рождаемости. Доходы (в частности заработная плата) вызывают интерес у экономистов. В зависимости от принятой экономической модели эффект может быть разным. В соответствии с подходом семейной экономики, пионером которым был Г. Беккер [Becker 1960], люди получают удовлетворение от наличия и воспитания детей и от их благополучия. Дети и, возможно, их качество сходны с потребительским товаром в функции полезности их родителей. В то время как исходная формулировка этой теории предполагает положительную связь между доходом и числом детей, большое количество последующих публикаций акцентировали внимание на отрицательной связи между доходами и рождаемостью, уделяя внимание двум аспектам [Jones et al. 2011]. Первый подход, фокусирующийся на компромиссе качества и количества, предложен Беккером и Льюисом [Becker, Lewis 1973] и Уиллисом [Willis 1973] (см. также [Becker et al. 1990]). Он исходит из того, что рост доходов может привести к уменьшению числа детей, так как родители с более высоким доходом ценят качество детей, но акцент на высоком качестве повышает затраты на то, чтобы их иметь (и воспитывать), и таким образом потенциально снижает уровень рождаемости. Ли и Мэйсон [Lee and Mason 2010] применяют эту модель, чтобы показать, что по мере увеличения доходов более низкая рождаемость связана с увеличением вложений в человеческий капитал детей.

Второй подход сосредоточивается на уnущенных возможностях в связи с рождением детей, особенно для женщин. Воспитание детей требует затрат родительского (особенно материнского) времени, поэтому рождаемость более затратна для семей, где матери имеют более высокие доходы, и поэтому в них можно ожидать меньше детей [Kravdal 1992]. Публикации на эту тему демонстрируют наличие значительного «денежного штрафа за материнство» для работающих женщин ("motherhood wage penalty"1), в связи с чем отсрочка деторождения предполагает значительный выигрыш для высокообразованных или профессионально активных женщин [Van Bavel 2010; Begall, Mills 2012]. Миллер [Miller 2010], к примеру, показал, что год отложенного материнства увеличивал доходы женщин на $9 \%$, их опыт работы на $6 \%$ и среднюю ставку заработной

1 Размер «штрафа за материнство» обычно устанавливается относительно заработной платы на основе результатов регрессионного анализа при сравнении индивидов, сходных по социально-экономическим и демографическим характеристикам, но различающихся числом детей (прим. переводчика). 
платы на 3\%. Другие расширили статическую модель Беккера, создав динамические экономические модели оптимального календаря для первого рождения (в основном применимые к женщинам), основанные на минимизации издержек деторождения, «штрафа в зарплате» и потери дохода [Happel et al. 1984; Cigno, Ermisch]. На теоретическом и эмпирическом уровнях они показали, что чем выше накопление человеческого капитала в процессе образования или чем выше отдача от образования, тем позже наступает материнство. Густафссон [Gustafsson 2001, 2002] пришел к выводу, что планирование женской карьеры было главным объяснением откладывания деторождения, и данный результат был позднее многократно воспроизведен в Швеции [Gustafsson 2005], Великобритании [Kneale and Joshi 2008], Ирландии [О’Donoghue et al. 2011], США [Amuedo-Dorantes, Kimmel 2005; Miller 2010] и Италии [Rondinelli et al. 2010].

Аналогичный подход был принят в многочисленных исследованиях, сфокусированных на изучении взаимосвязи между образованием, траекториями рынка труда и временем рождения первого ребенка. Предполагалось, что благодаря накоплению человеческого капитала женщины с более высоким уровнем образования имеют больше шансов сделать карьеру и повысить свои возможности получения заработка. Это также освобождает от необходимости замужества и рождения ребенка по экономическим причинам. Поскольку упущенная выгода в связи с рождением детей увеличивается с повышением человеческого капитала, высокообразованные женщины склонны откладывать вступление в брак и рождение ребенка. Такой подход был подвергнут критике Оппенгеймером [Oppenheimer 1994], который утверждает, что высокообразованные женщины имеют большую вероятность найти столь же высокообразованных партнеров. Это в свою очередь является стимулом для женщин вступать в брачные союзы и рожать детей по мере завершения образования (поскольку партнеры могут в дальнейшем объединить экономические ресурсы). В соответствии с подходом Оппенгеймера другие исследователи определили, что для более образованных женщин существует большая вероятность рождения ребенка (еще одного ребенка) и в целом характерен более высокий уровень рождаемости [Mencarini, Tanturri 2006; Mills et al. 2008], так как, во-первых, женщины могут иметь партнера с высоким образованием и, следовательно, высокой заработной платой [Behrman, Rosenzweig 2002]; во-вторых, они имеют более сильные позиции в своем союзе, что приводит к большему равенству прав при разделении домашнего труда; в-третьих, они могут передавать выполнение части домашних обязанностей третьим лицам. Хотя женщины с высшим образованием рожают первого ребенка позже, чем менее образованные, в некоторых исследованиях [Sobotka 2004; Kravdal, Rindfuss 2008] приводится утверждение, что более образованные наверстывают разницу в числе рожденных детей в более позднем возрасте. Или, другими словами, накопленный результат влияния позднего материнства на показатели рождаемости для детей более высоких порядков рождения (т.е. вторых или третьих) исчезает.

Результаты исследований взаимодействия между образованием и рождаемостью, однако, разнородны, и последние эмпирические данные показывают неочевидную связь между ними [Skirbekk 2008]. Маккрэри и Ройер [McCrary, Royer 2011] в ходе естественного эксперимента, связанного с различной политикой приема детей в школу в Калифорнии и в Teхасе (который был способен решить проблемы казуальности), обнаружили, что 
образование незначительно влияло на рождаемость. Несколько исследователей также нашли сильную обратную связь между уровнем образования и сроками первых родов в разных странах: [Rindfuss et al. 1980, 1996; Martin 2000] для США, [Joshi 2002] для Великобритании, [Lappegard 2002] для Норвегии, [Meron, Widmer 2002] для Франции, [Noguera et al. 2003] для Испании.

Другие исследователи вместо этого сосредоточились на важности самой включенности в получение образования, а не на уже достигнутом наиболее высоком его уровне. Результаты показывают, что индивиды, которые еще вовлечены в образовательный процесс, имеют меньшую вероятность родить ребенка, что связано с наличием “нормы последовательности событий”, при которой родительство следует за завершением образования: [Hoem 1986] для Швеции, [Goldscheider, Waite 1986] для США, [Blossfeld, Huinink 1991] для Германии, [Kravdal 1994] для Норвегии.

Ряд исследователей расширили это направление, рассмотрев такие важные моменты, связанные с образованием, как роль социализации личности и собственного выбора (“самоселективности”, “self-selection”) в занятости, следующей за образованием, которая в свою очередь влияет на рождаемость [Hoem et al. 2006; van Bavel 2010; Begall, Mills 2012]. Почти все исследования сосредоточены исключительно на женщинах, хотя имеются достойные внимания исключения. Винклер-Дворак и Тулемон [Winkler-Dworak, Toulemon 2007], например, определяют конвергенцию факторов, объясняющих возраст при рождении первого ребенка для женщин и мужчин.

\section{6. Неопределенность экономической ситуации и занятости}

Многие исследования, в основном социологические, сосредоточены на влиянии на рождаемость статуса занятости и особенно экономической неопределенности. Теории неопределенности (в основном экономической) напоминают теорию экономической депривации Истерлина [Easterlin 1976], согласно которой в периоды экономической нестабильности и роста безработицы тяга к вступлению в брак и рождению детей снижается. Эту же мысль развивал в своих работах Оппенгеймер [Oppenheimer 1988, 2003; Oppenheimer et al. 1997], который изучал воздействие неопределенности в возможности выполнения социальных и экономических ролей на сроки наступления семейных событий. Все большее число исследователей связывают экономическую нестабильность - часто в виде безработицы и неустойчивой ситуации на рынке труда - с откладыванием родительства. Для того чтобы эмпирически измерить воздействие неопределенности на переход к родительству в межстрановом контексте, Миллс и Блоссфельд [Mills, Blossfeld 2005] разработали схему, включающую три типа неопределенности: общеэкономическую (economic), стабильности занятости во времени (temporal) и в характере трудовых отношений (employment relations). Они обнаружили, что в условиях экономической неопределенности, которая измеряется масштабом нестабильности в занятости физических лиц (например, низкие заработки, безработица), молодежь откладывает долгосрочные обязательства, такие как родительство, которое требует определенного экономического базиса безопасности [Oppenheimer 1988] или того, что Риндфусс и Ванденхьювел [Rindfuss, Vandenheuvel 1990] назвали «условием допустимости» для появления в семье ребенка. Согласно Брину [Breen 1997], неопределенность в сроках занятости (часто вследствие 
временных или срочных контрактов) понижала способность молодежи брать на себя долгосрочные обязательства, такие как родительство. Наконец, работники, чьи трудовые отношения характеризуются более низкой неопределенностью (например, наемные работники по сравнению с самозанятыми или работающими по контрактам) испытывали затруднения в силу большей уязвимости их положения. Впрочем, влияние экономической неопределенности сильно ограничивается социальными институтами на национальном уровне, такими как государственная поддержка молодежи, защищающая молодых людей от экономической нестабильности, и гендерная политика, которая приводит к очень разному восприятию женщинами экономической неопределенности в разных национальных контекстах [Mills et. al 2005].

Крейенфельд [Kreyenfeld 2010] приходит к выводу, что и объективная экономическая неопределенность (безработица), и субъективная неопределенность (страх перед экономической ситуацией и необеспеченностью работой) незначительно влияют на отсрочку родительства, в то время как уровень образования является основной движущей силой процесса. Другими словами, малообразованные матери, несмотря на экономическую неопределенность, берут на себя роль матери, а высокообразованные, наоборот, откладывают рождение ребенка.

\section{7. Предпочтения в рождаемости}

Решения женщины или мужчины о рождении детей принимаются исходя из их собственных предпочтений, которые, как подчеркивают некоторые авторы, формируются на ранних этапах жизни человека. Теория предпочтений, предложенная Кэтрин Хаким [Hakim 2003], рассматривает в качестве центрального момента, определяющего репродуктивный выбор (как и выбор на рынке труда) в развитых обществах, различия в предпочтениях, касающихся образа жизни.

Хаким предполагает, что такие предпочтения более или менее постоянны на протяжении всей жизни и их можно объединить в три группы: ориентированные на карьеру, ориентированные на семью и ориентированные на совмещение работы и семьи. Эти жизненные предпочтения рассматриваются в качестве основной движущей силы наряду с политикой, учитывающей эту неоднородность. В своем сравнительном исследовании по странам Европы Витали с соавторами [Vitali et al. 2009] обнаружили, что у семейноориентированных женщин рождаемость наиболее высока, тогда как ориентированные на работу обычно имеют меньше детей или не имеют вообе (хотя направленность причинноследственной связи остается неясной). Другие исследователи [Mencarini, Tanturri 2006; Agrillo, Nelini 2008] выяснили, что среди прочих факторов предпочтения играют решающую роль в решении остаться добровольно бездетными или «чайлдфри». В то время как Агрилло и Нелини [Agrillo, Nelini 2008] приводят детальный обзор психологических и социологических факторов, ассоциирующихся с добровольной бездетностью, медицинские исследования часто сосредоточиваются на медико-биологических причинах, ведущих к бесплодию.

Исследование предпочтений в выборе пола ребенка показывает, что такие предпочтения повышают вероятность иметь больше детей, хотя и со значительными различиями между странами [Hank, Kohler 2000]. Андерссон и соавторы [Andersson et al. 
2006a, b], Миллс и Бегалл [Mills, Begall 2010], например, находят, что смешанные по полу предпочтения (т.е. желание иметь, по крайней мере, одного мальчика и одну девочку), заметно способствуют повышению вероятности рождения третьего ребенка для достижения этой цели.

\section{8. Межпоколенная передача ценностей и особенностей поведения}

Сходство репродуктивных биографий в сменяющих друга поколениях было также основной областью исследований, которые акцентировали внимание главным образом на стабильно положительной корреляции между количеством братьев и сестер и числом собственных детей [Berent 1953; Duncan et al. 1965; Johnson, Stokes 1976; Zimmer, Fulton 1980; Thornton 1980; Anderton et al. 1987; Axinn et al. 1994; Murphy, Wang 2001] или между возрастом при рождении первого ребенка у родителей и у их детей [Rijken, Liefbroer 2009]. Большинство исследований, касающихся темпа рождаемости, фокусируются на подростковом материнстве, показывая, что раннее материнство увеличивает риск рождения ребенка в молодом возрасте у потомков [Furstenberg et al. 1990; Horwitz et al. 1991; Kahn, Anderson1992; Manlove 1997]. Барбер [Barber 2000, 2001] и Стинхоф и Лифброер [Steenhof, Liefbroer 2008] также приходят к аналогичным выводам для старших возрастов и для мужчин. В рамках данных исследований передача особенностей поведения между поколениями была вызвана, по мнению исследователей, внутрисемейными процессами социализации, которые происходят в детстве и подростковом возрасте [Hendershot 1969; Thornton 1980; Axinn et al. 1994; Murphy, Wang 2001]. Предполагается, что родители передают семейные ценности, предпочтения, мнения, а также знания о контрацепции. Райкен и Лифброер [Rijken, Liefbroer 2009], однако, доказывают, что этот эффект полностью опосредуется собственной степенью религиозности детей. Переданные от поколения к поколению знания, установки и ценности можно рассматривать как индивидуальные особенности, которые имеют длительный эффект, так же, как генетическое наследие, передаваемое от родителей к детям.

\section{9. Биодемография рождаемости}

Наряду с механизмами социализации также рассматриваются биологические и генетические факторы, служащие для объяснения межпоколенного сходства в репродуктивных предпочтениях и в поведении [Wachter, Bulatao 2003]. Ряд исследований связывают биологические и генетические компоненты с репродуктивным поведением [Kohler et al. 1999; 2002a, b; Kohler, Rodgers 2003; Rodgers et al. 2008]. Эти исследования направлены на изучение взаимосвязи между рождаемостью, окружающей средой и генетическим складом индивидов и демонстрируют, что различия в генетическом складе влияют на результаты рождаемости и репродуктивное поведение. Здесь часто применяются исследования близнецов, сравнивающие однояйцевых (монозиготных) близнецов (практически с одинаковым генетическим строением) с двуяйцовыми (гетерозиготными). Это позволяет выделить, какая доля различий определяется генетической природой, а какая - одинаковой (например, воспитание в той же семье, обстановке) или разной (т.е. все другие факторы, такие как наличие разных партнеров) окружающей средой. Колер и соавторы [Kohler et al. 1999], например, использовали базу данных о близнецах из Дании для разграничения генетических и социальных факторов наследования количества детей, 
определив, что для более молодых поколений генетические факторы в значительной степени преобладали над предшествующими общими социальными (семейными) условиями.

Такого рода исследования являются частью формирующегося нового направления биодемографии рождаемости как междисциплинарной области исследований, которая объединяет теории общественных наук (социология, экономика) и такие подходы, как поведенческую и молекулярную генетику, нейроэндокринологию и эволюционную теорию [Wachter, Bulatao 2003]. Основной предпосылкой является то, что генетические и биологические особенности индивидов влияют на рождаемость либо прямо через генетически опосредованные изменения, либо, поскольку многие аспекты регулирования рождаемости имеют волевую составляющую (например, решение о возрасте рождения первого ребенка, предпочтения в рождаемости), косвенно через соответствующий темперамент либо другие особенности личности, влияющие на решения о рождении детей [Jokela et al. 2009]. Появляется все больше свидетельств того, что генетическая вариабельность изменяется с течением времени и в зависимости от уровня образования, а это означает, что важность социальных норм и индивидуальных решений также меняется во времени [Kohler et al. 1999; 2002a, b; Kohler, Rodgers 2003]. Биология рождаемости также претерпела революцию в результате стремительного распространения различных видов вспомогательных репродуктивных технологий (ВРТ). Благодаря быстрому распространению по всей Европе, ВРТ не только предоставляют новые возможности для расширения репродуктивных способностей для пар, которые хотят иметь детей в более позднем возрасте, но также позволяют стать родителями многим парам с прежде установленным бесплодием [de Mouzon et al. 2010].

\subsection{0. Социально-экономический статус и культурный контекст семьи происхождения}

Ряд исследований изучают влияние социально-экономического и культурного контекста семьи происхождения на возраст деторождения и принятие решения о числе детей. Некоторые исследования показали, что существует отрицательная корреляция между уровнем образования родителей (особенно образованием отца) и возрастом при рождении первого ребенка [Michael, Tuma 1985; Blossfeld, Huinink 1991; Billari 2001a, b], а также с числом детей [Murphy, Wang 2001; Rijken, Liefbroer 2009]. Отрицательная связь была также обнаружена между финансовым положением родителей (т.е. статусом занятости), (ожидаемым) числом детей [Thornton 1980; Murphy, Wang 2001] и возрастом при рождении первого ребенка [Rijken, Liefbroer 2009]. Эти данные позволяют предположить, что в более образованных и высокостатусных семьях иные цели, помимо создания семьи, более легко передаются вместе со стремлением к материальным благам [Easterlin 1969; Pampel, Peters 1995]. Поэтому, если стремление к потреблению высоко, родительство будет снижено или, по крайней мере, отложено. Это соответствует выводам, которые показывают отрицательное влияние занятости матерей (по сравнению с неработающими) на возраст при рождения первого ребенка [Barber 2000]. Еще одна, действующая в противоположном направлении, причина - религиозность родителей, положительно связанная с рождаемостью у их детей [Rijken, Liefbroer 2009]. 


\subsection{1. Обратная причинная связь на микроуровне}

В некоторых работах предпринимались попытки непосредственным образом обнаружить причинно-следственную связь между брачно-партнерским союзом и деторождением. Используя модели совместных рисков, построенные по данным США, Брайен и соавторы [Brien et al.1999] показали наличие общих факторов, ведущих к тому, что пребывание в партнерстве приводит к более высокой вероятности рождения ребенка. Сравнение сожительства и брака, основанное на аналогичных подходах с использованием уравнений совместных рисков, находится в центре внимания Баизан и соавторов [Baizán et al. 2003] для Испании, [Baizán et al. 2004] для Швеции и Германии, Ле Гофф [Le Goff 2002] для Франции и Западной Германии, Стил и соавторов [Steele et al. 2005, 2006] и Aacве с coавторами [Aassve et al. 2007] для Великобритании. Шпедер и Капитани [Spéder, Kapitany 2009], в свою очередь, используют в своих исследованиях фиксированные по времени репродуктивные намерения (т.е. намерения родить ребенка в течение 3 лет) и, рассматривая реализацию этих намерений, определяют факторы на микроуровне, которые повышают вероятность откладывания рождения ребенка за пределы запланированного временного отрезка.

Так же, как взаимосвязь между партнерством и рождаемостью, взаимосвязь между образованием и календарем деторождения может быть ложной (т.е. зависящей от общих наблюдаемых или ненаблюдаемых факторов), обратной или результатом одновременного выбора для индивида в двух жизненных сферах. Поэтому для того, чтобы должным образом оценить эффект образования (или профессиональной карьеры, или сферы образования) на возраст при первом рождении, должны быть приняты во внимание потенциальные проблемы эндогенности [Billari, Philipov 2004].

Другая тема, где причинность - ключевая проблема, это изучение взаимосвязи между деторождением и благополучием. Ограниченный, но растущий объем исследований выдвигает на первый план роль счастья как детерминанты рождаемости с согласующимися результатами для обоих полов. На основе Европейского социального исследования Биллари [Billari 2009] делает вывод, что счастливые люди с более высокой вероятностью намерены иметь (еще одного) ребенка, в то время как с помощью лонгитюдных данных по Австралии Парр [Parr 2010] установил, что удовлетворенность жизнью является детерминантной рождаемости.

Больше внимания уделялось исследованию противоположного направления взаимосвязи между деторождением и благополучием. Тогда как в ранних исследованиях было установлено, что в развитых странах дети пагубно влияли на брачно-семейное благополучие (cм. обзор [McLanahan, Adams 1987]), более поздние исследования связывают решение о рождении детей с благополучием различными другими способами. В последнее время теория «ценности детей» [Hoffman, Hoffman 1973; Hoffman, Manis 1979; Friedman et al. 1994] была переосмыслена как частный случай общей теории социальных функций (см., например, [Nauck 2007]), в рамках которой наличие детей рассматривается как инструмент, позволяющий индивиду достигать максимального физического и социального благополучия. В этом смысле рождение детей, когда рождаемость контролируется, способствует индивидуальному благополучию. Опираясь на этот подход, Колер и соавторы 
[Kohler et al. 2005] демонстрируют, что родительство вносит позитивный вклад в счастье родителей. Используя данные о близнецах из Дании и строгий эконометрический подход, учитывающий возможные источники эндогенности (например, генетические факторы), авторы выявляют нелинейное влияние наличия детей на счастье, особенно для женщин. Счастье женщин возрастает после первого ребенка, но дети последующих порядков не связаны с дальнейшим увеличением благополучия. В Европе было установлено, что родители были в целом счастливее, чем пары, не имеющие детей [Aassve et al. 2011]. Изучая динамичную взаимосвязь между рождением детей и счастьем, Пауэлс [Pouwels 2011] установил, что существует обратный U-образный эффект от рождения первого ребенка, который показывает, что в год до и после первых родов родители испытывают резкое повышение уровня счастья. Счастье, однако, по-видимому, начинает уменьшаться через несколько месяцев после родов, и молодые родители оказываются на том же уровне счастья, который был ранее в течение длительного времени. Марголис и Мюрскюля [Margolis, Myrskylä 2011] также исследуют возрастную и контекст-специфичную взаимосвязь между счастьем и деторождением.

Наконец, можно выделить еще одну группу исследований, где выявляется обратная причинная связь между областью полученного образования и возрастом при рождении первого ребенка: [Lappegard 2002; Lappegard, Rønsen 2005] для Норвегии, [Martin-Garcia, Baizan 2006] для Испании, [Neyer, Hoem 2008] для Австрии, [McDonald, Kippen 2009] для Австралии, [Van Bavel 2010] для нескольких стран, [Begall, Mills 2012] для Нидерландов. Эти исследования показывают, что более ранняя рождаемость распространена среди женщин, получивших образование в областях, связанных с более «женскими» сферами деятельности (например, обучение, здравоохранение), хотя отсутствует очевидная причинно-следственная связь. Женщины либо на основе собственного выбора определяют для себя образовательный путь в ту сферу занятости, где у них получается лучше сочетать материнство и работу, либо трудность сочетания карьеры и детей варьируется от избранного типа карьеры.

\section{3. МЕЗОУРОВЕНЬ ДЕТЕРМИНАНТОВ РОЖДАЕМОСТИ}

В последние годы все большее внимание уделяется разработке и применению теорий, которые учитывают тот факт, что люди как социальные субъекты одновременно и принимают решения, и действуют в системе социальных взаимодействий с семьей и сверстниками. В то время как некоторые исследования посвящены роли межличностных взаимодействий в формировании индивидуальных репродуктивных намерений, другие исследования сосредоточены на том, какое влияние оказывает место жительства на репродуктивный выбор. Наконец, существует еще одна тема исследований, рассматривающая социальную сеть как источник социального капитала в форме эмоциональной и материальной помощи. Осознание значимости социальных сетей в объяснении наблюдаемых моделей рождаемости до сих пор не подкреплено убедительными эмпирическими исследованиями. Главная причина заключается в отсутствии необходимых данных, трудностью моделирования и адекватного выявления социальных эффектов взаимодействия, а также отделения их влияния от селективных и 
контекстуальных факторов.

\section{1. Социальное взаимодействие}

Влияние социального взаимодействия на репродуктивный выбор привлекло значительное внимание [Bongaarts, Watkins 1996; Entwisle et al. 1996; Montgomery, Casterline 1996; Kohler 1997, 2001; Bernardi 2003]. Данные работы сосредоточены преимущественно на распространении методов контрацепции в развивающихся странах [Kohler et al. 2001] и указывают на два канала, через которые происходит социальное взаимодействие. Первый это социальное обучение, т.е. как индивиды получают знания от других людей, и второй социальное влияние, т.е. каким образом групповое единодушие сверстников накладывает ограничения на установки и реальное поведение [Montgomery, Casterline1996; Kohler et al.].

Небольшие качественные исследования в развитых странах показывают, что сетевые контакты индивида, например с коллегами или друзьями, являются ключевыми факторами в формировании его решений и о календаре, и о количестве рождений [Bernardi 2003; Bernardi et al. 2007; Keim et al. 2009; Rossier, Bernardi 2009; Bernardi, White 2009]. Люди смотрят на коллег, например, как на ключевой источник социального обучения, чтобы узнать, каким образом и насколько успешно они совмещают материнство с карьерой.

Однако до сих пор не хватает строгих количественных исследований. Насколько нам известно, только некоторые исследования применяли количественный подход. Аксинн и coавторы [Axinn et al. 1994] показали, что чем больше у человека племянников и племянниц, тем выше его предпочтения в отношении количества детей. Мански и Майшар [Manski, Mayshar 2003] интерпретируют особенности перехода в рождаемости в Израиле в свете социальных взаимодействий. Биллари и соавторы [Billari et al. 2009], интегрируя сетевой подход в Теорию запланированного поведения, считают, что социальное давление со стороны других релевантных людей значительно влияет на намерение женщин иметь ребенка. Бальбо и Миллс [Balbo, Mills 2011] в свою очередь обнаружили, что социальное давление со стороны родственников и друзей, настаивающих на рождении еще одного ребенка, связано с положительными намерениями родить второго или третьего ребенка. Обращаясь к календарю деторождения, несколько количественных исследований, направленных на изучение влияния социального взаимодействия, показывают, что, если сиблинг (брат/сестра) [Kuziemko 2006; Lyngstad, Prskawetz 2010] или сотрудник по работе [Hensvik, Nilsson 2010] рождает ребенка, вероятность для индивида также родить ребенка увеличивается. Эти исследования, адаптируя методы анализа истории событий, выявляют краткосрочный U-образный эффект, где «заразность» в поведении очень велика и повышается на 12-й [Lyngstad, Prskawetz 2010] или 24-й [Kuziemko 2006; Hensvik, Nilsson 2010] месяц после рождения ребенка у релевантного индивида (сотрудника или родственника). Позднее эффект понижается, становясь несущественным в долгосрочной перспективе. 
Апарисио Диас и соавторы [Diaz et al. 2011] применили инновационный подход, в котором используется агентное имитационное моделирование (agent-based model) ${ }^{2}$ с целью изучить влияние социальных взаимодействий на переход к родительству в Австрии в 19842004 гг. Результаты моделирования показали, что социальные взаимозависимости между людьми могут объяснить существенный сдвиг возраста первого рождения на более поздний, что и произошло в Австрии в прошедшие десятилетия.

\section{2. Место жительства}

Некоторые исследования свидетельствуют о различиях в рождаемости по месту жительства по нескольким направлениям. Во-первых, рождаемость продолжает варьироваться по регионам [Hank 2001, 2002; Caltabiano 2008; Kertzer et al. 2009]. Согласно Кулу [Kulu 2011], различия в желаемом числе детей объясняют дифференциацию рождаемости между малыми городами и сельскими ареалами, с одной стороны, и городскими агломерациями, с другой. Во-вторых, внутри агломераций пригороды устойчиво характеризуются более высоким уровнем рождаемости [Kulu et al. 2009], поскольку распространенные там односемейные домохозяйства связаны с более высокой рождаемостью [Kulu, Vikat 2007]. Эти различия сохраняются даже при условии контроля социально-экономических различий между территориями [Kulu, Boyle 2009], и таким образом можно предполагать, что контекстуальные факторы ареала проживания формируют репродуктивные намерения. Интересно отметить, что различия в уровне рождаемости между городом и селом существуют в течение долгого времени [Kulu et al. 2009], тогда как различия в календаре рождаемости появились совсем недавно. В результате, откладывание рождений более выражено в крупных, нежели в небольших населенных пунктах.

\section{3. Социальный капитал}

Исследования, сосредоточивающиеся на социальной сети как источнике социального капитала [Bühler, Philipov 2005; Philipov et al. 2006], опираются в основном на социологическую теорию [Lin et al. 2001; Flap, Völker 2004; Mandemakers, Dykstra 2008]. Социальный капитал определен как ресурсы, к которым люди имеют доступ через личные отношения, и может включать в себя товары, а также информацию, деньги, возможность работать, влияние, власть или активную помощь [Granovetter 1973; Bourdieu 1986; Coleman 1988]. Основываясь на предыдущих социологических исследованиях [Granovetter 1973; Bourdieu 1986; Lin et al. 2001; Flap, Völker 2004], некоторые демографы продемонстрировали, как социальный капитал (или его отсутствие) наряду с экономическими и культурными ресурсами влияет на решения о рождении детей [Schoen et al. 1997, Astone et al. 1999; Bühler, Philipov 2005; Philipov et al. 2006]. Это направление исследований изучает долгосрочные, стабильные и доверительные взаимоотношения (например, с членами семьи, прародителями, близкими друзьями или родственниками),

\footnotetext{
2 Метод имитационного моделирования, исследующий поведение децентрализованных агентов и то, как такое поведение определяет поведение всей системы в целом. В отличие от системной динамики, аналитик определяет поведение агентов на индивидуальном уровне, а глобальное поведение возникает как результат деятельности множества агентов, т.е. моделирование процессов строится «снизу вверх» (прим. переводчика).
} 
которые могут обеспечить индивида или семейную пару ресурсами, имеющими отношение к рождению детей. Следовательно, несмотря на то, что обмен этими ресурсами происходит лишь по случаю, т.е. когда в них есть нужда (например, неформальный уход за детьми, когда они маленькие), совокупность налаженных взаимоотношений, скорее всего, останется стабильной на протяжении всей жизни.

Большинство существующих исследований о социальном капитале как детерминанте (низкой) рождаемости было сосредоточено на экс-коммунистических странах Восточной Европы. Этот регион после распада Советского Союза пережил период экстремальной социально-экономической неопределенности. Бюлер и Филипов [Bühler, Philipov 2005] представляют широкую теоретическую дискуссию о том, как социальный капитал связан с социальными сетями и как это влияет на формирование репродуктивных намерений. Они также показывают, что в таком контексте поддерживающая сеть отношений и ресурсов играет решающую роль в персональных репродуктивных намерениях. Согласующиеся с этим аргументом другие эмпирические исследования показывают, что чем больше социальный капитал, тем выше вероятность того, что люди захотят родить (еще одного) ребенка ([Philipov 2002] для России, [Philipov et al. 2006] для Болгарии и Венгрии, [Bühler, Fratzcak 2007] для Польши) и захотят родить его скорее [Bühler, Philipov 2005; Philipov et al. 2006].

Бюлер и Фратцкек [Bühler, Fratzcak 2007] нашли положительное влияние социального капитала на рождаемость с учетом очередности рождений, особенно сильное для вторых детей. Что касается западноевропейских стран, то Хэнк и Крейенфельд [Hank, Kreyenfeld 2003] на примере Западной Германии обнаружили, что доступность неформального ухода за ребенком (т.е. ухода, обеспечиваемого бабушками и дедушками) увеличивает шансы для рождения первого ребенка. Бальбо и Миллс [Balbo, Mills 2011] показывают нелинейную связь (т.е. обратную U-образную) между неформальным уходом за детьми и желанием немецких мужчин иметь второго или третьего ребенка. Полное отсутствие помощи, так же как и наличие слишком многих источников помощи (т.е. нескольких разных людей), связаны с ослаблением намерений иметь еще одного ребенка, и в последнем случае это видимо связано с проблемой координации поддержки.

Американская литература сосредоточивается на поддержке, которую родственники оказывают матерям, включая уход за детьми и помощь в их воспитании, особенно это касается матерей-одиночек - здесь родственники рассматриваются как «сеть безопасности». Это особенно значимо по причине высокой нестабильности партнерств и многочисленности одиноких родителей [Swartz 2009], а потому особо пристальное внимание обращено на изучение «неблагополучных семей» [Harknett et al. 2001]. Харкнетт и Кнаб [Harknett, Knab 2007] обнаружили, что рождение детей от разных партнеров понижает помощь матерям деньгами, жильем и по уходу за ребенком, поскольку появляются трудности в поддержании отношений с родственниками. Харкнетт и Хартнетт [Harknett, Hartnett 2011] также обнаружили, что поддержка со стороны родственников и друзей чаще доступна для матерей, которые могут ответить взаимностью, а семьи с большим числом проблем имеют меньшую поддержку. 


\section{4. Спорные факторы и проблема обратной причинности на мезоуровне}

Признание важности социального взаимодействия в объяснении наблюдаемых тенденций рождаемости пока еще не подкреплено убедительными эмпирическими исследованиями. Главная причина заключается в недостатке удовлетворительных данных, трудностях моделирования и определения эффектов социального взаимодействия [Manski 1993, 1995]. Социальный контекст или другие факторы личностного уровня, общие для индивидуумов, могут также объяснять сходство в поведении (например, в одинаковых сроках деторождения) [Christakis, Fowler 2007; Cohen-Cole, Fletcher 2008; Bramoullé et al. 2009; Steglich et al. 2010; Fletcher 2011], а социальная сеть может быть выбрана в соответствии с желаемым поведением и меняться с течением времени.

Наконец, важно отметить, что ассоциация между местом жительства и репродуктивными предпочтениями вызывает вопрос о причинах и следствиях, так как связь может быть ложной и влияние возможно в обоих направлениях.

\section{4. ДЕТЕРМИНАНТЫ РОЖДАЕМОСТИ НА МАКРОУРОВНЕ}

Большой объем исследований посвящен тому, как влияют на репродуктивные решения культурные и институциональные условия, в которых существуют индивиды и семейные пары. Здесь может быть выявлена дихотомия - «экономика против культуры» [Billari 2004]. Тогда как часть исследований изучает, каким образом экономические тенденции, социальная политика, институциональные ограничения, тип социального государства влияют на темп и уровень рождаемости, другие сосредоточиваются на влиянии ценностей, установок и культуры на репродуктивное поведение. Более того, наряду с этими двумя подходами существуют и другие исследования макроуровня, в которых рассматривается роль контрацептивных технологий в динамике рождаемости. Еще раз: главный вызов для подобных работ заключается в том, как решать проблемы эндогенности и причинности, которые будут рассмотрены в конце этого раздела.

\section{1. Экономические тенденции}

Календарные эффекты, связанные с влиянием на рождаемость экономических тенденций, как правило, исследуются путем совместного рассмотрения КСР и макроэкономических показателей (например, ВВП и уровня безработицы). Как показали Соботка с соавторами [Sobotka et al. 2011], взаимосвязь КСР и ВВП неоднозначна. Используя данные по 26 странам-членам ОЭСР для периода 1971-2008 гг., они определили слабую корреляцию между изменениями в ВВП и КСР для календарных лет, утверждая, что это может быть результатом межстрановых различий. В некоторых исследованиях, посвященных развитым странам, выявляется проциклическая связь между экономическим ростом и рождаемостью. Мартин [Martin 2004], например, нашел, что более высокий ВВП связан с более высокой рождаемостью в Австралии. Снижение рождаемости во время экономических рецессий выглядит как результат откладывания деторождений, особенно первых детей, которое впоследствии может в значительной степени быть скомпенсированным во время 
экономического процветания [Neels 2010] . К аналогичным результатам пришли Колер и соавторы [Kohler et al. 2002a, b]; Миллс и Блоссфельд [Mills, Blossfeld 2005], Соботка с coавторами [Sobotka et al. 2010], считающие, что экономический спад приносит неуверенность, которая, в свою очередь, приведет к откладыванию деторождений. Некоторые эмпирические исследования также подтверждают эту гипотезу. По мнению Сантоу и Брахер [Santow, Bracher 2001] существует негативное влияние снижения ВВП на показатели рождаемости детей первой очередности в Швеции. Соботка и соавторы [Sobotka et al. 2011] показывают, что недавний экономический кризис, произошедший в 2008-2009 гг. в Европе и США, по всей видимости, ассоциируется со снижением рождаемости, скорее всего вызванным откладыванием деторождения.

Другие исследования, однако, приводят к противоположным результатам. Бац и Уорд [Butz, Ward 1979] предполагают, что экономические подъемы приводят к увеличению занятости женщин и как следствие к повышению расходов на детей в периоды экономического процветания. Поэтому тенденции рождаемости, вероятно, будут ацикличными. Макунович [Macunovich 1996] находит доказательства этого явления в США. Отрицательная взаимосвязь между экономическим ростом и откладыванием рождений также, по всей видимости, противоречит ряду недавних исследований. Биллингсли [Billingsley 2010] обнаружила, что динамика величины ВВП в Восточной Европе после 1990 г. положительно коррелирует с откладыванием рождений, и такой же результат наблюдается в Венгрии в отношении календаря первых рождений [Aassve et al. 2006]. Эти последние работы являются примерами большого числа исследований, которые рассматривают экономический кризис как объяснение резкого снижения рождаемости, характерного для стран Центральной и Восточной Европы после падения коммунизма. И вновь доказательства неоднозначны. Колер и Колер [Kohler, Kohler 2002], используя данные по России, обнаружили, например, отрицательную связь между снижением ВВП и КСР на макроуровне, но эта взаимосвязь не наблюдалась на микроуровне.

Недавно появился подход, привлекший большое внимание, который объясняет закономерности рождаемости и ее различия между странами с точки зрения социальноэкономического развития. Мюрскюля и соавторы [Myrskylä et al. 2009] представили доказательства фундаментальных изменений в хорошо известной отрицательной взаимосвязи между рождаемостью и развитием [Bryant 2007]. Они нашли, что в то время, как низкие и средние уровни так называемого индекса развития человеческого потенциала (ИРЧП) (Human Development Index, HDI) связаны с сохраняющейся низкой рождаемостью, более высокие уровни ИРЧП, видимо, способствуют рождаемости, переворачивая негативные тенденции.

Некоторые исследователи полагают, что вместо ВВП индекс потребительского доверия является лучшей мерой экономических рецессий, поскольку он отражает субъективное восприятие кризиса. Ван Гирсберген и де Бир [Van Giersbergen, de Beer 1997], Фоккема и соавторы [Fokkema et al. 2008] обнаруживают позитивную связь между данным индикатором и КСР в Нидерландах.

\section{2. Тенденции занятости/безработицы}

Экономическая неопределенность также изучалась при рассмотрении влияния 
безработицы на КСР. Исследования постоянно подтверждают наличие отрицательной связи: чем выше уровень безработицы, тем ниже уровень рождаемости [Macunovich 1996; Adserà 2004; Örsal, Goldstein 2010] или чаще откладываются первые и вторые рождения [Adserà 2010, 2011].

Другие исследования, адаптируя комплементарный подход, сосредоточены на взаимосвязи между трудовой занятостью женщин и КСР. Они показывают, что в странах ОЭСР эта ассоциация изменилась с отрицательной (когда у стран с более высокой занятостью женщин КСР был ниже) на положительную в течение 1980-х годов. Бенджамин [Benjamin 2001], Пэмпел [Pampel 2001], Ан и Мира [Ahn, Mira 2002] и Когель [Kögel 2004] представили некоторые теоретические объяснения и эмпирические свидетельства для описания изменения этой межстрановой корреляции. Однако возникает сомнение, не изменилась ли причинная связь между этими двумя переменными. Мишра и соавторы [Mishra et al. 2010], привлекая макроэконометрический анализ, направленный на исключение эндогенности, чтобы вскрыть причину и следствие, находят, что причинность идет от рождаемости (КСР) к участию женщин в рабочей силе, а не наоборот.

Другой подход к последствиям экономических тенденций был разработан Истерлином [Easterlin 1961, 1968]. В соответствии с этим подходом, циклические изменения в рождаемости в основном обусловлены колебаниями в коэффициентах рождаемости в прошлом, и соответственно размерами когорт. Представители многочисленных поколений сталкиваются с большей конкуренцией и, соответственно, с пониженными экономическими возможностями, что приводит к более низкой рождаемости (для получения более подробной информации см. обзор [Pampel, Peters 1995]).

\section{3. Политические меры}

Второй поток исследований был направлен на изучение воздействия мер политики (например, политики на рынке труда, налоговой, семейной или жилищной политики) на темпы и уровень рождаемости. Существуют разноречивые доказательства относительно эффективности мер социальной политики на рождаемость [Neyer 2003; Gauthier 2007; Hoem 2008; Mills et al. 2011]. Готье [Gauthier 2007] утверждает, что они, хоть и незначительно, влияют, скорее, на календарь рождений, чем на число детей.

Существует большое количество исследований, в которых изучаются эффекты предоставляемой помощи по уходу за ребенком на рождаемость. Большинство эмпирических исследований дают неоднозначные результаты. Тогда как по некоторым исследованиям, регионы, где слабо развита система помощи по уходу за ребенком, имеют более высокую рождаемость [Kravdal 1996; Rosen 2004], согласно другим, полагающим, что они принимают в расчет проблему эндогенности, доступность услуг по уходу за ребенком имеет положительное влияние на рождаемость [Del Boca 2002; Rindfuss et al. 2010]. Мануэлли и Сешадри [Manuelli, Seshadri 2009] разработали модель и провели эмпирический анализ, показавший, что более высокие налоговые ставки определяют низкую рождаемость. Системы социальной защиты и реформы в области социального обеспечения также рассматривались как детерминанты рождаемости [Cigno, Rosati 1992]. Актуальность фактора социальной защиты для репродуктивного выбора, кроме того, связана с идеей о возможной роли выросших детей в обеспечении социальной помощи пожилым, что 
касается и развитых обществ [Rendall, Bahchieva 1998; Mills, Begall 2010]. Галассо и coавторы [Galasso et al. 2009], к примеру, показали, что высокие государственные пенсии отрицательно связаны с рождаемостью.

Эффект семейной политики, подобно экономическим факторам, с которыми она тесно взаимосвязана [Hoem, Hoem 1997], варьируется в зависимости от институционального контекста и детерминант личностного уровня. По этой причине мало внимания было уделено чистому макроанализу, исследования фокусировались на изменениях временных рядов в пределах той или иной страны. Среди подобных исследований можно выделить статьи Эрмиш [Ermisch 1999], который считает, что щедрые пособия по уходу за ребенком в Великобритании поощряют молодое материнство; Хоэм [Hoem 2005], и Андерссон с соавторами [Andersson et al. 2006a, b], которые показывают, что отпуск для родителей по уходу ребенком уменьшает отсрочку деторождений в Швеции. Большинство исследований по мерам политики и срокам деторождения состоит либо из работ, выполненных на микроуровне (человека или семейной пары), где политика - одна из независимых переменных, либо из межстрановых сравнительных исследований (иногда многоуровневых) по странам с различной политикой. Хотя каждый подход имеет свои недостатки (подробное обсуждение см. [Neyer, Andersson 2008]), последние два метода позволяют провести проверку на наличие взаимодействия между аналитическими уровнями.

\section{4. Режнимы системы социильной защциты}

Основываясь на работах Эспинг-Андерсен [Esping-Andersen 1990, 1999], многочисленные исследователи объясняли различия между странами в рождаемости и жизненных стратегиях людей, соотнося их с различиями институциональными системами (например: [Mills and Blossfeld 2005]; см. также [Neyer 2003] - критика с позиций феминизма). По мнению Миллс и Блоссфельд [Mills, Blossfeld 2005], различные социальные режимы связаны с откладыванием рождаемости и их можно распределить по приоритету следующим образом: 1) политика активного поддержание устойчивой занятости на рынке труда (т.е. обязательство обеспечивать полную занятость); 2) политика, способствующая поддержанию благосостояния индивидов вне рынка труда (т.е. поддержка молодежи, безработных, больных, бедных, ухаживающих за членами семьи, пенсионеров); 3) политика в направлении щедрого размера семейных пособий и услуг (т.е. отпусков по беременности и родам/по уходу за маленькими детьми, услуг по уходу и воспитанию детей); 4) политика поддержания доли государственного сектора в рабочей силе. Этот набор политик создает в свою очередь сеть безопасности, на которую могут рассчитывать люди в случае безработицы, в случае необходимости регулировать свою занятость, в получении семейноориентированных услуг (уход за детьми, отпуска), которые в свою очередь способствуют или ограничивают принятие решение о рождении первого или последующих детей.

Можно выделить два вида режимов социальной защиты: фамилистический и нефамилистический. Нефамилистические режимы, где заботу о благосостоянии домохозяйств в значительной степени берет на себя не семья, а государство (такие как скандинавские социал-демократические страны) или рыночные механизмы (англосаксонские либеральные рыночные режимы), способствуют более высокой 
рождаемости. Напротив, фамилистические государства (консервативные и особенно южноевропейские режимы), где большинство экономических и обеспечивающих функций ложится на семью, а общественные институты также поддерживают традиционную модель разделения домашнего труда (т.е. так называемую модель мужчины-кормильца [Blossfeld, Drobnic 2001]), ограничивают рождаемость, что приводит к ее более низкому уровню.

Эти исследования в основном ведутся на теоретическом уровне. Исследователи сосредоточены на различных проявлениях отсутствия государственной поддержки, описывая, как эти факторы затрудняют совмещение работы и семьи, особенно для женщин, заставляя их выбирать между карьерой и материнством, что вызывает откладывание рождений или отказ от детей [Castles, Ferrera 1996; Mayer 2004]. Прямое эмпирическое исследование, связывающее конкретные режимы благосостояния непосредственно с рождаемостью, ограничено из-за сложности моделирования таких режимов; подобно исследованиям по социальной политике и рождаемости, оно состоит из анализа на микроуровне, где эффект различных режимов социальной защиты измеряется с помощью простых фиктивных переменных (dummy variables) или из межстрановых исследований (иногда многоуровневых), включающих страны с различными институциональными механизмами. Примеры таких эмпирических исследований приведены в заключительном разделе этой статьи (п.5), где обсуждается взаимодействие между микро- и макроуровнями.

\section{5. Изменения ценностей и установок}

Это направление исследований в значительной степени вытекает из теории «второго демографического перехода» (second demographic transition, SDT), разработанной Лестегом и ван де Каa [Lesthaeghe, van de Каa 1986] для интерпретации демографических изменений в промышленно развитых обществах. Согласно этой теории, массовые идейные изменения главным образом состоят в отказе от институционального контроля, акцентировании индивидуальной автономии и повышения потребностей в самореализации [Surkyn, Lesthaeghe 2004] - все это является движущей силой нового устройства семьи и поведенческих практик, среди которых откладывание рождений, меньшее число детей или бездетность, ставшие актуальными с 1960-х годов. Конструкция SDT была использована в качестве альтернативного [Lesthaeghe 1983] (в Бельгии) или дополнительного [Billingsley 2010] (для стран Восточной Европы) наряду с влиянием экономических циклов, объяснения вариаций в уровне рождаемости. Лестег [Lesthaeghe 2010: 242] как один из поборников этой теории подчеркнул, что «теория SDT полностью признает воздействие структурных изменений на макроуровне и экономической рационализации на микроуровне. Но ... теория SDT не рассматривает культурные изменения как эндогенные в любой экономической модели, они служат необходимой дополнительной силой вместе с их собственным экзогенным влиянием на демографические результаты».

Как подчеркнул Ван де Каa [van de Каa 1997], такие идейные изменения могут произойти в разные периоды и с различной интенсивностью в разных странах. В некоторых статьях, придерживающихся теории SDT, демонстрируется откладывание рождений в связи с увеличившейся самостоятельностью и независимостью личности: Лифброер [Liefbroer 2005] в Нидерландах и Бернар и Гольдшайдер [Bernhardt, Goldscheider 2006] в Швеции. Интересный подход в развитии этой теории был предложен Торнтоном и Филиповым 
[Thornton, Philipov 2009], в соответствии с которым идейные влияния и пересечение этих влияний со структурными факторами являются главными причинами снижения рождаемости в Центральной и Восточной Европе после падения Советского Союза.

Другие исследования фокусируются на влиянии изменения социальных норм на рождаемость. Несколько исследователей зафиксировали важность предельного возраста деторождения (т.е. возраста, после которого рождаемость становится социально неприемлемой) [Settersten, Hagestad 1996; Liefbroer, Billari 2010]. Биллари и соавторы [Billari et al. 2011] демонстрируют, что крайний возраст для деторождения положительно связан с распространением технологий ВРТ.

Подобно исследованиям режима социальной защиты, эти работы также в основном носят теоретический характер. Это прежде всего связано с трудностями в сборе данных о ценностных изменениях на уровне общества. Чтобы преодолеть эту проблему, некоторые исследователи [Liefbroer 2005; Bernhardt, Goldscheider 2006], эмпирически операционализируют изменения в ценностях и нормах, используя измерения на микроуровне индивидов, хотя они предполагают, что изменения ценностей происходят на уровне социума.

\section{6. Преемственность в культуре и истории}

Некоторые исследования объясняют корни нынешнего репродуктивного поведения исторической и культурной преемственностью (зависимость от пути) и приходят к выводам, полученным ранее Эспинг-Андерсеном [Reher 1998; Micheli 2000; Dalla Zuanna 2001]. Тем не менее в этих исследованиях, особо подчеркивающих важность культурного наследия, предполагается, что культура сформировала институциональную среду [РfauEffinger 1999].

Эту группу исследований можно разделить по водоразделу Север-Юг или ВостокЗапад (более детальный обзор см. [Billari 2004]). Разделение Европы на Восточную и Западную вдоль воображаемой линии Триест - Санкт-Петербург было впервые отмечено Хайналом [Hajnal 1965]. К западу от «линии Хайнала» характерен поздний и не всеобщий брак, в то время как к востоку брак был ранним и всеобщим. Историческая преемственность предоставляет объяснение более ранней рождаемости к востоку от линии Хайнала. Разделение на Север и Юг впервые предложил Реэр [Reher 1998], исходя из прочности межпоколенных семейных связей: в то время как южные страны характеризуются прочными семейными связями, в северных, как правило, они ослаблены. Основным доводом является то, что в системах характеризующихся сильными родственными и межпоколенными отношениями (например, фамилистические страны Южной Европы), и семьи имеют более низкую рождаемость [Dalla Zuanna 2001; Livi-Bacci 2001], молодые люди задерживают переход к взрослой жизни, в свою очередь, откладывая деторождение [Billari 2004]. Важно отметить, что фамилистические режимы сами по себе ни с институциональной, ни с культурной точек зрения не ведут к снижению рождаемости. Причины низкой рождаемости кроются, вероятно, во взаимодействии этих систем с недавним повышением статуса женщин в образовательной сфере и на рынке труда и с отсутствием институциональной поддержки для совмещения работы и семьи [Feyrer et al. 2008; Mills et al. 2008]. 
Исследования иммигрантов, связывающие рождаемость в месте происхождения и поведением лиц в стране «назначения», также показали существующую преемственность в культуре [Fernández, Fogli 2006, 2009] и поведении. Тем не менее мигранты часто обнаруживают в поведении черты, соответствующие их месту назначения, демонстрируя, что адаптация преобладает над избирательностью [Kulu 2005].

\section{7. Контрацептивные и репродуктивные технологии}

Дифференциация рождаемости на макроуровне объясняется не только «экономикой» и «культурой». Исследователи подробно изучали решающую роль «контрацептивной революции», повлиявшей и на уровень рождаемости [Frejka 2008], и на откладывание рождений (подробный обзор см. [Sobotka 2004]). Распространение современной контрацепции, в частности пилюль, радикально изменило природу процесса принятия решения о рождении детей, способствовало снижению числа детей и откладыванию деторождения [Goldi 2006]. Мерфи [Murphy 1993] утверждает, что краткосрочные изменения рождаемости в Англии и Уэльсе в 1970-х и начале 1980-х годов можно объяснить колебаниями в использовании контрацептивных пилюль из-за опасений их побочных эффектов. Бейли [Bailey 2010] использует изменения в законах, разрешающих продажу контрацептивов в отдельных штатах США, как естественный эксперимент, чтобы показать, что контрацепция действительно способствовала уменьшению коэффициентов рождаемости в этот период. Соботка и соавторы [Sobotka et al. 2010] оценивают влияние вспомогательных репродуктивных технологий (ВРТ) на рождаемость, используя данные по Дании. Ученые прогнозируют дальнейшее увеличение доли детей, родившихся в результате ВРТ, с имеющегося 5\%-ного вклада в КСР для когорты 1975 г. рождения. Кроме того, развитие ВРТ бросает вызов биологическим пределам откладывания деторождения [Billari et al. 2007] (см. анализ степени, в какой ВРТ влияет на вероятность стать родителем в пожилом возрасте [Leridon 2008]).

\section{8. Эндогенность политики и проблема обратной причинности на макроуровне}

Сложность отделения воздействия мер политики от других наблюдаемых и ненаблюдаемых факторов часто приводят к несостоятельным попыткам обнаружить эффекты политики в рождаемости. Трудно отделить воздействие какой-либо специальной политики от широкого набора политических инструментов, которые потенциально влияют на рождаемость, и весьма проблематично эмпирически установить, была ли успешна эта политика, так как имеется некоторое запаздывание ответной реакции по отношению к моменту инициирования политики. Наконец, существует проблема эндогенности в политике, когда она не только воздействует на рождаемость и вызывает изменения, но и сама часто является реакцией на изменения рождаемости, становясь неотъемлемой чертой этих изменений. Строгий анализ приводится в работе Кальвия [Kalwij 2010], где он обнаружил положительное влияние на уровень рождаемости увеличения расходов на программы семейной политики, которые помогают женщинам совмещать семью и работу, тем самым снижая упущенную выгоду, связанную с рождением детей. Налоговая политика, которая позволяет легче реализовывать квазиэкспериментальные стратегии, привлекла внимание многих экономистов. Положительное влияние налоговых стимулов на уровень 
рождаемости было обнаружено в Германии [Buttern, Lutz 1990], Швеции [Walker 1995], Канаде [Milligan 2005] и США [Whittington 1993]. Готье и Хатциус [Gauthier, Hatzius 1997], использовав панельные данные по странам, пришли к более противоречивым результатам.

\section{5. Дискуссия}

Наш обзор показывает, что исследования рождаемости в развитых странах весьма обширны и продолжают разрастаться с применением инновационных подходов. Главной целью этой статьи была оценка текущего состояния исследований рождаемости для классификации и определения различных подходов и вновь полученных знаний. Вторичная цель систематизация существующих исследований, соответствующим трем (макро-, мезо- и микроаналитическим) уровням подходов и результатов. Мы также уделили значительное внимание вопросам причинности и эндогенности.

Вначале мы продемонстрировали значительные успехи по нескольким направлениям в изучении детерминант на микроуровне. В дополнение к рассмотрению ключевых детерминант, таких как занятость, доход и образование (и нюансов в этих областях), многообещающие новые и инновационные исследования были сосредоточены на том, как воздействуют на рождаемость гендерное разделение труда, состав семьи (например, повторные браки), предпочтения и межпоколенная передача ценностей и поведенческих практик. Несмотря на то, что недавно были зафиксированы успехи в освоении новых тем, таких как биологические и генетических основы рождаемости и новые семейные формы, остается еще много задач, которые должны быть решены в ходе будущих исследований.

Во-первых, это обеспечение наличия и доступности данных, содержащих необходимую информацией, таких как биомаркеры или генетические данные, а также данных, относящихся к новым типам семейных форм. Объем данных, которые сочетают в себе результаты генетических и социальных обследований, хотя и растет, но все равно остается ограниченным. Во-вторых, необходимо проведение серьезных исследований в области биодемографии, которые должны происходить при сотрудничестве с экспертами из различных дисциплин. Это даст возможность понять, как правильно интегрировать этот тип информации и знания о биологических механизмах в наши теоретические, но одновременно и статистические модели.

В этом обзоре также освещаются основные мезоуровневые факторы, влияющие на рождаемость, в том числе изучаемые развивающейся областью исследований социального взаимодействия, социальный капитал, социальные сети и место жительства. Хотя растущее количество (в первую очередь качественных) работ направлено на исследование этих факторов мезоуровня, основные проблемы по-прежнему остаются. Как было отмечено ранее, отсутствует крупномасштабная база количественных данных, собранных для изучения влияния социальных сетей на рождаемость. Среди данных, которые были собраны, измерения социальных сетей остаются ограниченными. Это частично объясняется высокими затратами на сбор такой информации, а также интенсивной нагрузкой на 
респондентов при ее сборе, что создает проблемы для включения этих данных в программу исследования.

На макроуровне мы обобщили основные изучавшиеся детерминанты: от тенденций в экономике и занятости/незанятости до мер политики, режимов социального обеспечения, изменения ценностей и установок, преемственности в истории и культуре, использования контрацепции и новых репродуктивных технологий. Как отмечалось ранее, ключ к решению проблемы надежной интеграции этих факторов на макроуровне для понимания рождаемости - это переход от чисто теоретических рассуждений к более убедительным эмпирическим исследованиям взаимосвязей. Хотя исследователи часто заявляют о воздействия на репродуктивное и другие виды демографического поведения факторов макроуровня, таких как система социального обеспечения или социальные ценностей, имеется немного успешных попыток эмпирически подкрепить эти заявления. На всех уровнях мы также обращаемся к проблемам, связанным с обратной причинной связью и неоднозначными факторами, а для факторов макроуровня - к проблемам эндогенности социальной политики, которые мы подробнее обсудим позже.

Понимание некоторых общих проблем современных исследований, которое можно извлечь из внимательного чтения этого обзора, может способствовать успешным исследованиям в будущем. Две проблемы, которые стали очевидными во время подготовки обзора, - это четкие границы между дисциплинами и географическими зонами.

Во-первых, исследования рождаемости требуют междисциплинарности, т.е. в объяснении вопросов, связанных с календарем и уровнем рождаемости должны участвовать представители нескольких дисциплин. Однако примеры междисциплинарных исследований, в которые были бы одновременно вовлечены представители разных дисциплин или где приняты теоретические и/или методологические подходы различных дисциплин, немногочисленны. Принятый порядок цитирования преимущественно ограничен конкретной дисциплиной, более того, в статьях часто игнорируются релевантные публикации из других дисциплин. Легко предположить, что исследования рождаемости серьезно выиграют, если пересечение дисциплинарных границ будет происходить чаще, начиная хотя бы с более частого чтения статей друг друга.

Во-вторых, это значимость географических границ. Так, исследования рождаемости в Европе проводят главным образом европейские ученые, исследования в Северной Америке - североамериканские, иными словами, основная масса исследований рождаемости часто не сообщаются друг с другом. Это было отмечено в нескольких местах нашего обзора, когда приводились противоречащие теории и выводы, представленные североамериканскими и европейскими исследователями. Темы, подходы (включая тип данных) и, опять же, цитаты остаются каким-то образом не связанными, хотя исследования в Европе явно фундаментальны в выявлении роли факторов макроуровня, в основном благодаря возможностям межстранового сравнительного анализа. Неудивительно, что ученые, работающие в других развитых областях науки, более успешны в наведении мостов через Атлантику. Кроме того, легко предположить, что, соединив выводы и подходы, касающиеся всех развитых обществ, можно было бы сформировать общее понимание закономерностей репродуктивного выбора. 
Две дополнительные проблемы, связанные с методами, данными и аналитическими стратегиями, становятся очевидными, когда мы осмысливаем наш литературный обзор в более общих терминах. Во-первых, это касается международных исследований рождаемости. Несмотря на усилия по созданию сравнительных, агрегированных данных (таких, например, как База данных по рождаемости, разработанная Институтом демографических исследований Общества Макса Планка и Венским институтом демографии), большинство исследований фокусируется на микроданных, которые обычно не допускают высокую сравнимость исследований. Таким образом, можно было бы продвинуть исследования рождаемости путем создания коллекции сопоставимых микроуровневых данных исследований рождаемости по многим странам, включая, что очень важно, США и Японию. Это еще более имеет смысл, учитывая повышение географической мобильности населения между странами. Только дальнейшие совместные усилия исследователей и финансирующих организаций позволят раскрыть фундаментальные механизмы, действующие на различных уровнях и влияющие на репродуктивный выбор. Во-вторых, поскольку исследователи могут только наблюдать рождаемость (в отличие от экспериментально вызываемых явлений), вопрос об истинной причинности в противоположность ложным зависимостям остается основной проблемой. Внимание к проблеме причинности неоднородно в литературе, но несомненно преобладание работ, вырастающих из традиций экономики. Причинные интерпретации широко распространены также в исследованиях, которые обнаруживают связи (это серьезная проблема), но некоторые из них явно не направлены на понимание или изучение причинности (проблема более низкого порядка, внимание к которой связано с амбициями исследователей и самих дисциплин). Дальнейшие шаги по признанию важности методов, направленных на раскрытие причинности в наблюдаемых данных, будут способствовать проведению исследований рождаемости более высокого качества. Исследователи и политики в равной степени выиграли бы от принятия программ по оценке мер политики, которые могут повлиять на выбор людей в сфере деторождения.

Кроме того, наш обзор выявил три возникшие проблемы, касающиеся изучения действующих факторов в диапазоне от индивидуальных до контекстных. Исследования мужчин или, другими словами, мужской рождаемости и отцовства остаются весьма немногочисленными, хотя их количество и растет. Очевидно, что гендерный подход является необходимым, но это означает, что оба пола должны играть равную роль в нашем понимании репродуктивного выбора. Большее число исследований, включающих и мужчин, и женщин, позволило бы углубить наши знания. Вторая проблема вытекает из первой - проблема супружеских пар. Как по теоретическим причинам, так и по причинам, связанным с отсутствием данных, проблема репродуктивного выбора изучается только применительно к индивиду. Ограниченные исследования и данные о семейных парах доказывают чрезвычайно важное значение совместного решения о рождении ребенка. Третья проблема заключается в ограниченном знании о важности факторов мезоуровня. Здесь теория развита больше, чем реальные инструменты, такие как сбор количественных данных об имеющихся родственниках и/или сетевой подход, к которому мы обращались ранее. Многообещающим выглядит использование инновационных аналитических техник, таких как агентное моделирование. Недавние инновационные проекты (например, лонгитюдное исследование здоровья подростков и взрослых - Add Health study - в США или 
Панельное исследование родственных отношений в Нидерландах - Netherlands Kinship Panel Study) также дают представление о будущих направлениях исследований.

Наконец, перспективными научно-исследовательскими направлениями представляются те, в которых акцент делается на взаимодействии факторов разного аналитического уровня. Как уже упоминалось в разделах о политике и социальных режимах, исследования, использующие сравнительный межстрановой подход к изучению жизненных циклов, часто рассматривают национально-специфичные институты как зависящие от пути структуры, которые формируют индивидуальные характеристики на микроуровне, способствуя или препятствуя возможности иметь детей или иметь их в определенный период жизни (во время обучения или без прекращения работы). Национальные социальные институты или действующие силы, такие как системы занятости и образования, режимы социальной защиты, социальная политика, семья и гендерные системы, исторически обусловлены, специфичны для стран и определяют степень, с которой воздействуют на людей изменения на макроуровне [Mayer 2004]. Микроуровневые факторы, такие как брачно-партнерский статус, могут взаимодействовать с макроуровневыми институтами и культурой. Одним из примеров является разница между сожительством и браком как детерминантами деторождения. Баизан и соавторы [Baizán et al.2004] нашли, что в Швеции, в отличие от Западной Германии, эта разница практически не заметна. Сравнивая когорты 1958 и 1970 г. рождения в Великобритании, Стил и соавторы [Steele et al. 2006] показали, что связь между сожительством и рождением детей исторически усилилась из-за изменения культурных факторов. Женщины могут принять решение отложить рождение ребенка, чтобы избежать брака, особенно в обществах, где менее развито гендерное равенство (например, в Японии), потому что они не хотят быть принужденными к материнству и прекращению работы [Rindfuss et al. 2004].

Ранее в этом обзоре мы уже упоминали исследования, которые применяя межстрановой подход, показали, как силы и ограничения, действующие на макроуровне, могут повлиять на микроуровневую динамику. Кальвий [Kalwij 2010], Бегалл и Миллс [Begall, Mills 2011], например, показывают, как разные режимы социальной защиты и семейная политика могут способствовать или препятствовать достижению баланса между семьей и работой на индивидуальном уровне.

Гендерная теория Макдональда [McDonald 2000a, b] и связанные с ней подходы [Chesnais 1996; Esping-Andersen 1999, 2009] являются наиболее походящими примерами анализа взаимодействия между факторами на микроуровне (положение в занятии и гендерное равенство в семье) и факторами макроуровня (режимом социальной защиты в государстве) [Cooke, Baxter 2010]. Макдональд утверждает, что очень низкая рождаемость имеет место там, где и когда высокий уровень гендерного равенства в индивидуальноориентированных институтах, таких как образование и рынок труда, сочетается с низким уровнем гендерного равенства в семье и семейно-ориентированных институтах. Иными словами, если возможности женщин в системе образования и на рынке труда близки к тем, которыми обладают мужчины, но использование этих возможностей женщинами сильно ограничено из-за наличия детей, поскольку они не могут совмещать работу и материнство, то в среднем женщины будут стремиться к ограничению числа детей. Хотя эта теория часто 
используется в объяснении низкой рождаемости, эмпирических доказательств попрежнему не хватает [Mills 2010].

Другой пример мезо- и макровзаимодействия - исследование Бальбо и Миллс [Balbo, Mills 2011], показавшее, что общественное давление и социальный капитал в значительной степени фильтруются на институциональном уровне. Они оказывают более сильное влияние на индивидуальные намерения иметь еще одного ребенка в фамилистических странах, где обязанности по уходу за детьми возлагаются на семью и поощряется модель мужчины-кормильца.

\section{БЛАГОДАРНОСТИ}

Комментарии и замечания многих людей при подготовке этой рукописи способствовали ее улучшению. Авторы хотели бы поблагодарить членов исследовательской группы из Университета Гронингена «Социальное неравенство и жизненный курс», а также Гвидо Альфани, Джанпьеро Далла Зуанна, Фрэнка Ф. Фюрстенберга и Росса Макмиллана. Исследование Франческо С. Биллари было поддержано грантом Министерства образования, университетов и научных исследований Италии (PRIN 2009). Исследование Мелинды Миллс поддерживается грантом Нидерландского научного фонда (VIDI Grant 452-10-012). Авторы также благодарны за ценные советы анонимному рецензенту и редактору European Journal of Population.

\section{ОткРЫтЫЙ достУП}

Эта статья распространяется на условиях лицензии Creative Commons Attribution, которая разрешает ее использование, распространение и воспроизведение любым способом, при условии указания автора (авторов) и источника.

\section{ЛИТЕРАТУРА}

Aassve A., F.C. Billari, Z. Spéder (2006). Societal transition, policy changes and family formation: evidence from Hungary // European journal of population. 22(2): 127-152.

Aassve A., F.C. Billari, R. Piccarreta (2007). Strings of adulthood: a sequence analysis of young British women's work-family trajectories // European journal of population. 23(3-4): 369388.

Aassve A., A. Goisis, M. Sironi (2011). Happiness and childbearing across Europe // Social indicators research: $1-22$.

Adserà A. (2004). Changing fertility rates in developed countries. The impact of labor market institutions // Journal of population economics. 17: 17-43.

Adserà A. (2010). Where are the babies? Labor market conditions and fertility in Europe // European journal of population. 27(1): 1-32.

Adserà A. (2011). The interplay of economic uncertainty and education in explaining second births in Europe // Demographic research. 25(16): 513-544. 
Agrillo C., C. Nelini (2008). Childfree by choice: a review // Journal of cultural geography. 25: $347-363$.

Ahn N., P. Mira (2002). A note on the changing relationship between fertility and female employment rates in developed countries // Journal of population economics. 15: 667-682.

Ajzen I. (1991). The theory of planned behavior // Organizational behavior and human decision processes. 50(2): 179-211.

Amuedo-Dorantes C., J. Kimmel (2005). The motherhood wage gap for women in the United States: the importance of college and fertility delay // Review of economics of the household. 3: $17-48$.

Andersson G., K. Hank, M. Rønsen, A. Vikat (2006a). Gendering family composition: sex preferences for children and childbearing behavior in the Nordic countries // Demography. 43(2): 255-267.

Andersson G., J.M. Hoem, A.Z. Duvander (2006b). Social differentials in speed-premium effects in childbearing in Sweden // Demographic research. 14(4): 51-70.

Anderton D.L., N.O. Tsuya, L.L. Bean, G.P. Mineau (1987). Intergenerational transmission of relative fertility and life course pattern // Demography. 24: 467-480.

Aparicio Diaz B., T. Fent, A. Prskawetz, L. Bernardi (2011). Transition to parenthood: the role of social interaction and endogenous networks // Demography. 48(2): 559-579.

Astone N.M., C.A. Nathanson, R. Schoen, Y.J. Kim (1999). Family demography, social theory, and investment in social capital // Population and development review. 25(1): 1-31.

Axinn W.G., M.E. Clarkberg, A. Thornton (1994). Family influences on family size preferences // Demography. 31: 65-79.

Bailey M.J. (2010). Momma's got the pill. How Anthony Comstock and Griswold v. Connecticut shaped US childbearing // American economic review. 100(1): 98-129.

Baizán P., A. Aassve, F.C. Billari (2003). Cohabitation, marriage, and first birth: the interrelationship of family formation events in Spain // European journal of population. 19(2): 147-169.

Baizán P., A. Aassve, F.C. Billari (2004). The interrelations between cohabitation, marriage and first birth in Germany and Sweden // Population and environment. 25(6): 531-561.

Balbo N., M. Mills (2011). Social capital and pressure in fertility decision-making: second and third births in France, Germany and Bulgaria // Population studies. 65(3): 335-351.

Barber J.S. (2000). Intergenerational influences on the entry into parenthood: Mothers' preferences for family and non-family behavior // Social forces. 79: 319-348.

Barber J.S. (2001). The intergenerational transmission of age at first birth among married and unmarried men and women // Social science research. 30: 219-247.

Becker G.S. (1960). An economic analysis of fertility // Demographic and economic change in developed countries / G.S. Becker, ed. Princeton: Princeton university press: 209-231.

Becker G.S., H.G. Lewis (1973). On the interaction between the quantity and quality of children // Journal of political economy. 81(2): 279-288.

Becker G.S., K.M. Murphy, R. Tamura (1990). Human capital, fertility, and economic growth // Journal of political economy. 98(5): 12-37. 
Begall K., M. Mills (2011). The impact of perceived work control, job strain and work-family conflict on fertility intentions: a European comparison // European journal of population. 27(4): 433-456.

Begall K., M.C. Mills (2012). The influence of educational field, occupation, and occupational sex segregation on fertility in the Netherlands // European sociological review. doi:10.1093/esr/jcs051.

Behrman J.R., M.R. Rosenzweig (2002). Does increasing women's schooling raise the schooling of the next generation? // American economic review. 92(1): 323-334.

Benjamin K. (2001). Men, women, and low fertility: analysis across time and country. Unpublished working paper: University of North Carolina.

Berent J. (1953). Relationship between family sizes of the successive generations // Milbank memorial fund quarterly bulletin. 31: 39-50.

Bernardi L. (2003). Channels of social influence on reproduction // Population research and policy review. 22: 527-555.

Bernardi L., R. White (2009). Close kin influences on fertility behaviour // Family, kinship and state in contemporary Europe / P. Heady, M. Kohli, eds. Perspectives on theory and policy. Vol.3. Frankfurt: Campus.

Bernardi L., S. Keim, H. von der Lippe (2007). Social influences on fertility: a comparative mixed methods study in eastern and western Germany // Journal of mixed methods research. 1: $23-47$.

Bernhardt E., F. Goldscheider (2006). Gender equality, parenthood attitudes, and first births in Sweden // Vienna yearbook of population research, 2006: 19-39.

Berrington A. (2004). Perpetual postponers? Women's, men's and couple's fertility intentions and subsequent fertility behavior // Population trends. 117: 9-19.

Billari F.C. (2001a). A log-logistic regression model for a transition rate with a starting threshold // Population studies. 55(1): 15-24.

Billari F.C. (2001b). A sickle transition rate model with starting threshold // Statistical methods and applications. 10: 139-155.

Billari F.C. (2004). Becoming an adult in Europe: A macro(/micro)-demographic perspective // Demographic research. 3(2): 13-44.

Billari F.C. (2009). The happiness commonality: fertility decision in low-fertility settings // How generations and gender shape demographic change / UNECE, ed. New York/Geneva: United Nations: 7-38.

Billari F.C., H.-P. Kohler (2004). Patterns of low and lowest-low fertility in Europe // Population studies. 58(2): 161-176.

Billari F.C., H.-P. Kohler, G. Andersson, H. Lundstro"m (2007). Approaching the limit: longterm trends in late and very late fertility // Population and development review. 33: 149-170.

Billari F.C., D. Philipov (2004). Education and the transition to motherhood: a comparative analysis of Western Europe // European demographic research paper. 3. Vienna Institute of demography.

Billari F.C., D. Philipov, M. Testa (2009). Attitudes, norms and perceived behavioural control: explaining fertility intentions in Bulgaria // European journal of population. 25(4): 439-465. 
Billari F.C., A. Goisis, A.C. Liefbroer, R.A. Settersten, A. Aassve, G. Hagestad et al. (2011). Social age deadlines for the childbearing of women and men // Human reproduction. 26(3): $616-622$.

Billingsley S. (2010). The post-communist fertility puzzle // Population research and policy review. 29(2): 193-231.

Blossfeld H.-P., S. Drobnic (2001). Careers of couples in contemporary societies: a crossnational comparison of the transition from male breadwinner to dual earner families. Oxford: Oxford university press.

Blossfeld H.-P., J. Huinink (1991). Human capital investments or norms of role transition? How women's schooling and career affect the process of family formation // American journal of sociology. 97: 143-168.

Blossfeld H.-P., E. Klijzing, M. Mills, K. Kurz (2005). Globalisation, uncertainty, and youth in society. London: Routledge.

Bongaarts J. (2001). Fertility and reproductive preferences in post-transitional societies // Population and development review. 27: 260-281.

Bongaarts J. (2002). The end of the fertility transition in the developed world // Population and development review. 28(3): 419-443.

Bongaarts J., G. Feeney (1998). On the quantum and tempo of fertility // Population and Development Review. 24: 271-291.

Bongaarts J., S. Watkins (1996). Social interactions and contemporary fertility transitions // Population and development review. 22(4): 639-682.

Bourdieu P. (1986). The forms of capital // Handbook of theory and research for the sociology of education / J.G. Richardson, ed. New York: Greenwood: 241-258.

Bramoullé Y., H. Djebbari, B. Fortin (2009). Identification of peer effects through social networks // Journal of econometrics. 150(1): 41-55.

Breen R. (1997). Risk, recommodification and stratification // Sociology. 31(3): 473-489.

Brien M.J., L.A. Lillard, L.J. Waite (1999). Interrelated family-building behaviors: Cohabitation, marriage, and nonmarital conception // Demography. 36(4): 535-551.

Bryant J. (2007). Theories of fertility decline and the evidence from development indicators // Population and development review. 33: 101-127.

Buber I., A. Prskawetz (2000). Fertility in second unions in Austria: findings from the Austrian FFS // Demographic research. 3(2).

Buchmann M.C., I. Kriesi (2011). Transition to adulthood in Europe // Annual review of sociology. 37: 481-503.

Bühler C., E. Fratczak (2007). Learning from others and receiving support: the impact of personal networks on fertility intentions in Poland // European societies. 9(3): 359-382.

Bühler C., D. Philipov (2005). Social capital related to fertility: theoretical foundations and empirical evidence from Bulgaria // Vienna yearbook of population research, 2005: 53-81.

Bumpass L., J. Sweet, A. Cherlin (1991). The role of cohabitation in declining rates of marriage // Demography. 53: 913-927.

Butler D. (2004). The fertility riddle // Nature. 432: 38-39. 
Buttern T., W. Lutz (1990). Estimating fertility responses to policy measures in the German Democratic Republic // Population and development review. 16(3): 539-555.

Butz W.P., M.P. Ward (1979). The emergence of countercyclical U.S. fertility // The American economic review. 69(3): 318-328.

Caldwell J.C., T. Schindlmayr (2003). Explanations of the fertility crisis in modern societies: a search for commonalities // Population studies. 57(3): 241-263.

Caltabiano M. (2008). Has the fertility decline come to an end in the different regions of Italy? New insights from a cohort approach // Population. 63(1): 157-172.

Castles F.G., M. Ferrera (1996). Home ownership and the welfare state: is Southern Europe different? // South European society \& politics. 1(2): 163-185.

Chesnais J.-C. (1996). Fertility, family, and social policy // Population and development review. 22(4): 729-739.

Christakis N.A., J.H. Fowler (2007). The spread of obesity in a large social network over 32 years // New England journal of medicine. 357(4): 370-379.

Cigno A., J. Ermisch (1989). A microeconomic analysis of the timing of first births // European economic review. 33: 737-760.

Cigno A., F.C. Rosati (1992). The effects of financial markets and social security on saving and fertility behaviour in Italy // Journal of population economics. 5(4): 319-341.

Cohen S.B., J.A. Sweet (1974). The impact of marital disruption and remarriage on fertility // Journal of marriage and family. 36: 87-96.

Cohen-Cole E., J.M. Fletcher (2008). Is obesity contagious? Social networks vs. environmental factors in the obesity epidemic // Journal of health economics. 27(5): 1382-1387.

Coleman J.S. (1988). Social capital in the creation of human capital // American journal of sociology. 94 (Supp): 95-120.

Cooke L.P. (2009). Gender equity and fertility in Italy and Spain // Journal of social policy. 38(1): $123-140$.

Cooke L.P., J. Baxter (2010). "Families" in international context: comparing institutional effects across western societies // Journal of marriage and family. 72(3): 516-536.

Corijn M., E. Klijzing (2001). Transitions to adulthood in Europe. Dordrecht: Kluwer.

Corijn M., A.C. Liefbroer, J. De Jong Gierveld (1996). It takes two to tango, doesn't it? The influence of couple characteristics on the timing of the birth of the first child // Journal of marriage and family. 58: 117-126.

Dalla Zuanna G. (2001). The banquet of Aeolus: a familistic interpretation of Italy's lowest low fertility // Demographic research. 4(5): 133-162.

De Mouzon J., V. Goossens, S. Bhattacharya et al. (2010). Assisted reproductive technology in Europe, 2006: results generated from European registers by ESHRE // Human reproduction. 25: $1851-1862$.

Del Boca D. (2002). The effect of child care on participation and fertility // Journal of population economics. 15(3): 549-573.

Dommermuth L., J.E. Klobas, T. Lappega ${ }^{\circ}$ rd (2009). Now or later? The theory of planned behavior and fertility intentions. Dondena working paper. Milan: Carlo F. Dondena Centre for research on social dynamics. 
Duncan O.D., R. Freedman, J.M. Coble, D.P. Slesinger (1965). Marital fertility and size of family of orientation // Demography. 2: 508-515.

Easterlin R.A. (1961). The American baby boom in historical perspective // American economic review. 51: 869-911.

Easterlin R.A. (1968). Population, labor force, and long swings in economic growth: the American experience. New York: Columbia university press.

Easterlin R.A. (1969). Towards a socioeconomic theory of fertility: a survey of recent research on economic factors in American fertility // Fertility and family planning: a world view / S.J. Behrman, L. Corsa Jr., R. Freedman, eds. Ann Arbor: University of Michigan press: 127156.

Easterlin R.A. (1976). The conflict between aspirations and resources // Population and development review. 2(3): 417-425.

Entwisle B., R.R. Rindfuss, D.K. Guilkey, A. Chamratrithirong, S.R. Curran, Y. Sawangdee (1996). Community and contraceptive choice in rural Thailand: A case study of Nang Rong // Demography. 33: 1-11.

Ermisch J. (1999). Prices, parents, and young people's household formation // Journal of urban economics. 45(1): 47-71.

Esping-Andersen G. (1990). The three worlds of welfare capitalism. Oxford: Polity press.

Esping-Andersen G. (1999). Social foundations of postindustrial economies. Oxford: Oxford university press.

Esping-Andersen G. (2009). The incomplete revolution: adapting welfare states to women's new roles. Cambridge: Polity press.

Fernández R., A. Fogli (2006). Fertility: The role of culture and family experience // Journal of the European economic association. 4(2-3): 552-561.

Fernández R., A. Fogli. (2009). Culture: an empirical investigation of beliefs, work, and fertility // American economic journal: Macroeconomics. 1(1): 146-177.

Feyrer J., B. Sacerdote, A. Stern (2008). Will the stork return to Europe? Understanding fertility within developed nations // Journal of economic perspectives. Summer. 22(3): 3-22.

Flap H., B. Vo“lker (2004). Creation and returns of social capital: a new research program. London: Routledge.

Fletcher J.M. (2011). Peer influences on adolescent alcohol consumption: evidence using an instrumental variables/fixed effect approach // Journal of population economics. doi:10.1007/s00148-011-0365-9.

Fokkema T., H. de Valk, J. de Beer, C. van Duin (2008). The Netherlands: childbearing within the context of a "Poldermodel"' society // Demographic research. 19(21): 743-794.

Frejka T. (2008). Birth regulation in Europe. Completing the contraceptive revolution // Demographic research. 19: 73-84.

Frejka T., G.W. Jones, J.-P. Sardon (2010). East Asian childbearing patterns and policy developments // Population and development review. 36: 579-606.

Friedman D., M. Hechter, S. Kanazawa (1994). A theory of the value of children // Demography. 31: 375-401.

Furstenberg F.F.Jr, J.A. Levine, J. Brooks-Gunn (1990). The children of teenage mothers: patterns of early childbearing in two generations // Family planning perspectives. 22: 54-61. 
Galasso V., R. Gatti, P. Profeta (2009). Investing for the old age: pensions, children and savings // International tax and public finance. 16(4): 538-559.

Gauthier A. (2007). The impact of family policies on fertility in industrialized countries: a review of the literature // Population research and policy review. 26: 323-346.

Gauthier A., J. Hatzius (1997). Family benefits and fertility: an econometric analysis // Population studies. 51: 295-306.

Gibson-Davis C.M., K. Edin, S. McLanahan (2005). High hopes but even higher expectations: the retreat from marriage among low-income couples // Journal of marriage and family. 67: 1301-1312.

Goldin C. (2006). The quiet revolution that transformed women's employment, education, and family // American economic review. 96(2): 1-21.

Goldscheider F.K., L.J. Waite (1986). Sex differences in the entry into marriage // American journal of sociology. 92: 91-109.

Goldstein J., W. Lutz, M.R. Testa (2003). The emergence of sub-replacement family size ideals in Europe // Population research and policy review. 22(5): 479-496.

Goldstein J.R., T. Sobotka, A. Jasilioniene (2009). The end of lowest-low fertility? // Population and development review. 35(4): 663-700.

Granovetter M. (1973). The strength of weak ties // American journal of sociology. 78(6): 13601380.

Gustafsson S.S. (2001). Optimal age at motherhood. Theoretical and empirical considerations on postponement of maternity in Europe // Journal of population economics. 14(2): 225-247.

Gustafsson S.S. (2005). Having kids later. Economic analyses for industrialized countries // Review of economics of the household. 3(1): 5-16.

Hajnal J. (1965). European marriage patterns in perspective // Population in history / D.S. Glass, D.E.C. Eversley, eds. London: Edward Arnold: 101-143.

Hakim C. (2003). A new approach to explaining fertility patterns: Preference theory // Population and development review. 29(3): 349-374.

Hank K. (2001). Regional fertility differences in western Germany: an overview of the literature and recent descriptive findings // International journal of population geography. 7(4): 243257.

Hank K. (2002). Regional social contexts and individual fertility decisions: a multilevel analysis of first and second births in western Germany // European journal of population. 18(3): 281299.

Hank K., H.-P. Kohler (2000). Gender preferences for children in Europe: empirical results from 17 FFS countries // Demographic research. 2(1): 133-144.

Hank K., M. Kreyenfeld (2003). A multilevel analysis of child care and women's fertility decisions in western Germany // Journal of marriage and family. 65(3): 584-596.

Happel S.K., J.K. Hill, S.A. Low (1984). An economic analysis of the timing of childbirth // Population studies. 38: 299-311.

Harknett K.S., C.S. Hartnett (2011). Who lacks support and why? An examination of mothers' personal safety nets // Journal of marriage and family. 73(4): 861-875.

Harknett K., J. Knab (2007). More kin, less support: Multipartnered fertility and perceived support among mothers // Journal of marriage and family. 69(1): 237-253. 
Harknett K., L. Hardman, I. Garfinkel, S.S. McLanahan (2001). The fragile families study: social policies and labor markets in seven cities // Children and youth services review. 23(6-7): $537-555$.

Heaton T.B., C.K. Jacobson, K. Holland (1999). Persistence and change in decisions to remain childless // Journal of marriage and family. 61(2): 531-539.

Hendershot G.E. (1969). Familial satisfaction, birth order, and fertility values // Journal of marriage and family. 31: 27-33.

Hensvik L., P. Nilsson (2010). Business, buddies and babies. IFAU Working paper.

Heuveline P., J.M. Timberlake (2004). The role of cohabitation in family formation: the United States in comparative perspective // Journal of marriage and family. 66: 1214-1230.

Hirschman C. (1994). Why fertility changes // Annual review of sociology. 20: 203-233.

Hobcraft J., K. Kiernan (1995). Becoming a parent in Europe. Vol. 1 // European population conference / EAPS-IUSSP, ed. Milan: Franco Angeli: 27-65.

Hoem J.M. (1986). The impact of education on modern family-union initiation // European journal of population. 2: 113-133.

Hoem J.M. (2005). Why does Sweden have such high fertility? // Demographic research. 13(22): $559-572$.

Hoem J.M. (2008). Overview chapter 8: The impact of public policies on European fertility // Demographic research special collection. 7(19): 249-260.

Hoem B., J.M. Hoem (1997). Sweden's family policies and roller-coaster fertility. Jinko Mondai Kenkyu // Journal of population problems. 52: 1-22.

Hoem J.M., G. Neyer, G. Andersson (2006). Educational attainment and childlessness: the relationship between educational field, educational level, and childlessness among Swedish women born in 1955-59 // Demographic research 14: 331-380.

Hoffman L.W., M.L. Hoffman (1973). The value of children to parents // Psychological perspectives on population / J.T. Fawcett, ed. New York: Basic Books: 19-76.

Hoffman L.W., J.D. Manis (1979). The value of children in the United States: a new approach to the study of fertility // Journal of marriage and family. 41(3): 583-596.

Horwitz S.M., L.V. Klerman, H.S. Kuo, J.F. Jekel (1991). Intergenerational transmission of school-age parenthood // Family planning perspectives. 23(168-172): 177.

Iacovou M., L.P. Tavares (2011). Yearning, learning, and conceding: reasons men and women change their childbearing intentions // Population and development review. 37(1): 89-123.

Jansen M.D., A.C. Liefbroer (2006). Couples' attitudes, childbirth and the division of labor // Journal of family issues. 27: 1487-1511.

Jefferies J., A. Berrington, I. Diamond (2000). Childbearing following marital dissolution in Britain // European journal of population. 16: 193-210.

Johnson, N. E., \& Stokes, C. S. (1976). Family size in successive generations: the effects of birth order, international change in lifestyle, and familial satisfaction // Demography. 13: 175-187.

Jokela M., M. Kivima“ki, M. Elovainio, L. Keltikangas-Ja“rvinen (2009). Personality and having children: a two-way relationship // Journal of personality and social psychology. 96(1): 218230. 
Jones L.E., A. Schoonbroodt, M. Tertilt (2011). Fertility theories. Can they explain the negative fertility-income relationship? // Demography \& the economy / J.B. Shoven, ed. Chicago: University of Chicago Press: 43-100.

Joshi H. (2002). Production, reproduction and education: women, children and work in a British perspective // Population and development review. 28: 445-474.

Kahn J.R., K.E. Anderson (1992). Intergenerational patterns of teenage fertility // Demography. 29: 39-57.

Kalwij A. (2010). The impact of family policy expenditure on fertility in western Europe // Demography. 47(2): 503-519.

Keim S., A. Kla“rner, L. Bernardi (2009). Qualifying social influence on fertility intentions: composition, structure, and meaning of fertility-relevant social networks // Current sociology. 57(6): 1-20.

Kertzer D.I., M.J. White, L. Bernardi, G. Gabrielli (2009). Italy's path to very low fertility: the adequacy of economic and second demographic transition theories // European journal of population. 25(1): 89-115.

Kneale D., H. Joshi (2008). Postponement and childlessness: evidence from two British cohorts // Demographic research. 19: 1935-1968.

Kögel T. (2004). Did the association between fertility and female employment within OECD countries really change its sign? // Journal of population economics. 17(45): 65.

Kohler H.-P. (1997). Learning in social networks and contraceptive choice // Demography. 34: 369-383.

Kohler H.-P. (2001). Fertility and social interaction. An economic perspective. Oxford: Oxford university press.

Kohler H.-P., I. Kohler (2002). Fertility decline in Russia in the early and mid 1990s: the role of economic uncertainty and labour market crises // European journal of population. 18(3): 233262.

Kohler H.P., J.L. Rodgers (2003). Education, fertility, and heritability: explaining a paradox // Offspring: Fertility behavior in biodemographic perspective / K.W. Wachter, R.A. Bulatao, eds. Washington, DC: National Academies press: 46-90.

Kohler H.P., J.L. Rodgers, K. Christensen (1999). Is fertility behavior in our genes? Findings from a danish twin study // Population and development review. 25: 253-288.

Kohler H.-P., J.R. Behrman, S.C. Watkins (2001). The density of social networks and fertility decisions: evidence from South Nyanza District, Kenya // Demography. 38(1): 43-58.

Kohler H.P., F.C. Billari, J.A. Ortega (2002a). The emergence of lowest-low fertility in Europe during the 1990s // Population and development review. 28: 641-681.

Kohler H.-P., J.L. Rodgers, K. Christensen (2002b). Between nurture and nature: the shifting determinants of female fertility in Danish twin cohorts 1870-1968 // Social biology. 49: 218248.

Kohler H.-P., J.R. Behrman, A. Skytthe (2005). Partner ? children = happiness? The effects of partnerships and fertility on well-being // Population and development review. 31(3): 407445. 
Kravdal Ø. (1992). The emergence of a positive relation between education and third birth rates in Norway with supportive evidence from the United States // Population studies. 46(3): 459475.

Kravdal Ø. (1994). The importance of economic activity, economic potential and economic resources for the timing of firth birth in Norway // Population studies. 48: 249-267.

Kravdal Ø. (1996). How the local supply of day-care centers influences fertility in Norway: a parityspecific approach // Population research and policy review. 15(3): 201-218.

Kravdal Ø., R.R. Rindfuss (2008). Changing relationships between education and fertility: a study of women and men born 1940 to 1964 // American sociological review. 73: 854-873.

Kreyenfeld M. (2010). Uncertainties in female employment careers and the postponement of parenthood in Germany // European sociological review. 26(3): 351-366.

Kulu H. (2005). Migration and fertility: competing hypotheses re-examined // European journal of population. 21(1): 51-87.

Kulu, H. (2011). Why do fertility levels vary between urban and rural areas? // Regional studies. $1-17$.

Kulu H., P.J. Boyle (2009). High fertility in city suburbs: compositional or contextual effects? // European journal of population. 25(2): 157-174.

Kulu H., A. Vikat (2007). Fertility differences by housing type: the effect of housing conditions or of selective moves? // Demographic research. 17(26): 775-802.

Kulu H., P. Boyle, G. Andersson (2009). High suburban fertility: evidence from four Northern European countries // Demographic research. 21(31): 915-944.

Kuziemko I. (2006). Is having babies contagious? Fertility peer effects between adult siblings. Princeton university (working paper).

Lappegard T. (2002). Education attainment and fertility pattern among Norwegian women. Documents 2002/18. Department of social statistics, Statistics Norway, Oslo.

Lappegard T., M. Rønsen (2005). The multifaceted impact of education on entry into motherhood // European journal of population. 21: 31-49.

Le Goff J.-M. (2002). Cohabiting unions in France and in West Germany. Transitions to first birth and first marriage // Demographic research. 7(18): 594-624.

Lee R., A. Mason (2010). Fertility, human capital, and economic growth over the demographic transition // European journal of population. 26(2): 159-182.

Leridon H. (2008). A new estimate of permanent sterility by age: Sterility defined as the inability to conceive // Population studies. 62(1): 15-24.

Lesthaeghe R. (1983). A century of demographic and cultural change in Western Europe: an exploration of underlying dimensions // Population and development review. 9(3): 411-435.

Lesthaeghe R. (2010). The unfolding story of the second demographic transition // Population and development review. 36(2): 211-251.

Lesthaeghe R., D. van de Kaa (1986). Twee demografische transities? (Two demographic transitions?) // Bevolking-Groei en krimp, mens en maatschappij / Lesthaeghe, van de Kaa, eds. Deventer: Van Loghum Slaterus: 9-24.

Liefbroer A.C. (2005). The impact of perceived costs and rewards of childbearing on entry into parenthood: evidence from a panel study // European journal of population. 21(4): 367-391. 
Liefbroer A.C. (2009). Changes in family size intentions across young adulthood: a life-course perspective // European journal of population. 25(4): 363-386.

Liefbroer A.C., F.C. Billari (2010). Bringing norms back in: a theoretical and empirical discussion of their importance for understanding demographic behavior // Population, space and place. 16(4): 287-305.

Lillard L.A., J.L. Waite (1993). A joint model of marital childbearing and marital disruption // Demography. 30: 653-681.

Lin N., K.S. Cook, R.S. Burt. (2001). Social capital: Theory and research. New Brunswick: Aldine Transaction.

Livi-Bacci M. (2001). Too few children and too much family // Daedalus. 130: 139-156.

Lutz W., B.C. O’Neill, S. Scherbov (2003). Europe's population at a turning point // Science. 299: 1991-1992.

Lyngstad T.H., A. Prskawetz (2010). Do siblings' fertility decisions influence each other? // Demography. 47(4): 923-934.

Macunovich D.J. (1996). Relative income and price of time: exploring their effects on US fertility and female labor force participation // Population and development review. 22: 223 257.

Mandemakers J.J., P.A. Dykstra (2008). Discrepancies in parent's and adult child's reports of support and contact // Journal of marriage and family. 70(2): 495-506.

Manlove J. (1997). Early motherhood in an intergenerational perspective: the experiences of a British cohort // Journal of marriage and family. 59: 263-297.

Manski C.F. (1993). Identification of endogenous social effects: the reflection problem // The review of economic studies. 60(3): 531-542.

Manski C.F. (1995). Identification problems in social sciences. New York: Harvard university press.

Manski C.F., J. Mayshar (2003). Private incentives and social interactions: Fertility puzzles in Israel // Journal of the European economic association. 1(1): 181-211.

Manuelli R.E., A. Seshadri (2009). Explaining international fertility differences // Quarterly journal of economics. 124(2): 771-807.

Margolis R., M. Myrskylä (2011). A global perspective on happiness and fertility // Population and development review. 37(1): 29-56.

Martin S.P. (2000). Diverging fertility among U.S. women who delay childbearing past age 30 // Demography. 37: 523-533.

Martin J. (2004). The ultimate vote of confidence': Fertility rates and economic conditions in Australia, 1976-2000 // Australian social policy 2002-2003. Canberra: Commonwealth of Australia: 31-54.

Martin-Garcia T., P. Baizan (2006). The impact of type of education and of educational enrolment on first births // European sociological review. 22: 259-275.

Matthews B. (1999). The gender system and fertility: An exploration of the hidden links // Canadian studies in population. 26(1): 21-38.

Mayer K.U. (2004). Whose lives? How history, societies, and institutions define and shape life courses // Research in human development. 1(3): 161-187. 
McCrary J., H. Royer (2011). The effect of female education on fertility and infant health: evidence from school entry policies using exact date of birth // American economic review. 101(1): 158-195.

McDonald P. (2000a). Gender equity in theories of fertility transition // Population and development review. 26(3): 427-439.

McDonald P. (2000b). Gender equality, social institutions and the future of fertility // Journal of population research. 17: 1-16.

McDonald P., R. Kippen (2009). Fertility in South Australia: an overview of trends and socioeconomic differences, 2009. Report to the Department of trade and economic development. Adelaide: Government of South Australia.

McLanahan S., J. Adams (1987). Parenthood and psychological well-being // Annual review of sociology. 13: 237-257.

Mencarini L., M.L. Tanturri (2006). High fertility or childlessness: micro-level determinants of reproductive behaviour in Italy // Population. 61(4): 389-416.

Meron M., I. Widmer (2002). Unemployment leads women to postpone the birth of their first child // Population. 57(2): 301-330.

Michael R.T., N.B. Tuma (1985). Entry into marriage and parenthood by young men and women: the influence of family background // Demography. 22: 515-544.

Micheli G.A. (2000). Kinship, family and social network: the anthropological embedment of fertility change in Southern Europe // Demographic research. 3(13).

Miller A.R. (2010). The effect of motherhood timing on career path // Journal of population economics. 24(3): 1071-1100.

Miller W.B. (2011). Comparing the TPB and the T-D-I-B framework // Vienna yearbook of population research. 9(1): 19-29.

Miller W.B., D.J. Pasta (1994). The psychology of child timing: a measurement instrument and a model // Journal of applied social psychology. 24: 218-250.

Miller Torr B.M., S.E. Short (2004). Second births and the second shift: a research note on gender equity and fertility // Population and development review. 30: 109-130.

Milligan K. (2005). Subsidizing the stork: new evidence on tax incentives and fertility // Review of economics and statistics. 87(3): 539-555.

Mills M. (2004). Stability and change: the structuration of partnership histories in Canada, the Netherlands and the Russian Federation // European journal of population. 20: 141-175.

Mills M. (2010). Gender roles, gender (in)equality and fertility: an empirical test of five gender equity indices // Canadian population studies. 37(3/4): 445-474.

Mills M., K. Begall (2010). The impact of gender preferences on third Births in Europe: a multilevel examination of men and women // Population studies. 64(1): 77-95.

Mills M., H.-P. Blossfeld (2005). Globalization, uncertainty and the early life course: a theoretical framework // Globalization, uncertainty and youth in society/ H.-P. Blossfeld, E. Klijzing, M. Mills, K. Kurz, eds. London/New York: Routledge advances in sociology serie: $1-24$.

Mills M., L. Mencarini, M.L. Tanturri, K. Begall (2008). Gender equity and fertility intentions in Italy and the Netherlands // Demographic research. 18(1): 1-26. 
Mills M., R.R. Rindfuss, P. McDonald, E. te Velde (2011). Why do people postpone parenthood? Reasons and social policy incentives // Human reproduction update. 17(6): 848860.

Mishra V., I. Nielsen, R. Smyth (2010). On the relationship between female labour force participation and fertility in G7 countries: evidence from panel cointegration and Granger causality // Empirical economics. 38(2): 361-372.

Montgomery M.R., J.B. Casterline (1996). Social influence, social learning, and new models of fertility // Fertility in the United States: new patterns, new theories / J. Casterline, R. Lee, K. Foote, eds.: 87-99.

Morgan S.P., C.A. Bachrach (2011). Is the theory of planned behaviour an appropriate model for human fertility? // Vienna yearbook of population research. 9(1): 11-18.

Morgan S.P., H. Rackin (2010). The correspondence between fertility intentions and behavior in the United States // Population and development review. 36(1): 91-118.

Morgan S.P., M.G. Taylor (2006). Low fertility at the turn of the twenty-first century // Annual review of sociology. 32: 375-399.

Murphy M. (1993). The contraceptive pill and women's employment as factors in fertility change in Britain 1963-1980: a challenge to the conventional view // Population studies. 47(2): 221-243.

Murphy M., D. Wang (2001). Family-level continuities in childbearing in low-fertility societies // European journal of population. 17: 75-96.

Myers S.M. (1997). Marital uncertainty and childbearing // Social forces. 75: 1271-1289.

Myrskylä M., H.-P. Kohler, F.C. Billari (2009). Advances in development reverse fertility declines // Nature. 460(7256): 741-743.

Nauck B. (2007). Value of children and the framing of fertility: results from a cross-cultural comparative survey in 10 societies // European sociological review. 23(5): 615-629.

Neels K. (2010). Temporal variation in unemployment rates and their association with tempo and quantum of fertility: some evidence for Belgium, France and the Netherlands. Paper presented at the Annual meeting of the Population association of America, Dallas, 17 April.

Neyer G. (2003). Family policies and low fertility in Western Europe. Rostock: Max Planck Institute for demographic research (MPIDR Working paper).

Neyer G., G. Andersson (2008). Consequences of family policies on childbearing behavior: effects or artifacts? // Population and development review. 34: 699-724.

Neyer G.R., J.M. Hoem (2008). Education and permanent childlessness: Austria vs. Sweden; a research note // Demographic challenges for the 21st century: a state of the art in demography / J. Surkyn, P. Deboosere, J. Van Bavel, eds. Brussels: VUBPRESS.

Noguera C.S., K. Golsch, N. Stainhage (2003). Increasing uncertainty in the Spanish labour market and entry into parenthood // Genus. 58(1): 77-119.

O’Donoghue C., D. Meredith, E. O'Shea (2011). Postponing maternity in Ireland // Cambridge journal of economics. 35(1): 59-84.

OECD (2011). Doing better for families. OECD Publishing.

Olah L.S. (2003). Gendering fertility: Second births in Sweden and Hungary // Population research and policy review. 22: 171-200. 
Oppenheimer V.K. (1988). A theory of marriage timing // American journal of sociology. 94: $563-591$.

Oppenheimer V.K. (1994). Women's rising employment and the future of the family in industrial societies // Population and development review. 20: 293-342.

Oppenheimer V.K. (2003). Cohabiting and marriage during young men's career-development process // Demography. 40: 127-149.

Oppenheimer V.K., M. Kalmijn, N. Lim (1997). Men's career development and marriage timing during a period of rising inequality // Demography. 3: 311-330.

Örsal D.D.K., J.R. Goldstein (2010). The increasing importance of economic conditions for fertility. MPIDR Working Paper WP 2010-014. Rostock: Max Planck Institute for demographic research.

Pampel F.C. (2001). The institutional context of population change. Chicago: The University of Chicago press.

Pampel F.C., H.E. Peters (1995). The Easterlin effect // Annual review of sociology. 21: 163194.

Parr N. (2010). Satisfaction with life as an antecedent of fertility: partner ? happiness $=$ children? // Demographic research. 22(21): 635-661.

Pfau-Effinger B. (1999). Change of family policies in the socio-cultural context of European societies // Family policies. Yearbook comparative social research (135-159) / A. Leira, ed. Stamford: JAI press.

Philipov D. (2002). Fertility in times of discontinuous societal change: the case of Central and Eastern Europe. MPIDR Working paper 2002-024. Rostock: Max Planck Institute for demographic research.

Philipov D. (2009). Fertility intentions and outcomes: The role of policies to close the gap // European journal of population. 25: 355-361.

Philipov D., Z. Speder, F.C. Billari (2006). Soon, later, or ever? The impact of anomie and social capital on fertility intentions in Bulgaria (2002) and Hungary (2001) // Population studies. 60(3): 289-308.

Pouwels B.J. (2011). Work, family, and happiness: essays on interdependencies within families, life events, and time allocation decisions. PhD dissertation. Utrecht: Utrecht university.

Prskawetz A., A. Vikat, D. Philipov, H. Engelhardt (2003). Pathways to stepfamily formation in Europe: results from the FFS // Demographic research. 8(5): 107-149.

Quesnel-Vallé A., S.P. Morgan (2003). Missing the target? Correspondence of fertility intentions and behavior in the U.S. // Population research and policy review. 22: 497-525.

Reher D.S. (1998). Family ties in western Europe: persistent contrasts // Population and development review. 24(2): 203-234.

Rendall M.S., R.A. Bahchieva (1998). An old-age security motive for fertility in the United States? // Population and development review. 24(2): 293-307.

Rijken A.J., A.C. Liefbroer (2009). The effects of relationship quality on fertility // European journal of population. 25: 27-44.

Rijken A.J., E. Thomson. (2011). Partners' relationship quality and childbearing // Social science research. 40(2): 485-497. 
Rindfuss R., A. Vandenheuvel (1990). Cohabitation: a precursor to marriage or an alternative to being single? // Population and development review. 16(4): 703-726.

Rindfuss R.R., L. Bumpass, C. St. John (1980). Education and fertility: implications for the roles women occupy // American sociological review. 45: 431-447.

Rindfuss R.R., S.P. Morgan, K. Offutt (1996). Education and changing age pattern of American fertility: 1963-1989 // Demography. 33: 277-290.

Rindfuss R.R., M.K. Choe, L.L. Bumpass, N.O. Tsuya (2004). Social networks and family change in Japan // American sociological review. 69: 838-861.

Rindfuss R.R., D.K. Guilkey, S.P. Morgan, O. Kravdal (2010). Child-care availability and fertility in Norway // Population and development review. 36(4): 725-748.

Rodgers J.L., H.P. Kohler, M. McGue, J.R. Behrman., I. Petersen, P. Bingley et al. (2008). Education and cognitive ability as direct, mediating, or spurious influences on female age at first birth: behaviour genetic models fit to Danish Twin data // American journal of sociology. 114(Supp): 202-232.

Rondinelli C., A. Aassve, F.C. Billari (2010). Women's wages and childbearing decisions: evidence from Italy // Demographic research. 22(19): 549-578.

Rosen M. (2004). Fertility and public policies-evidence from Norway and Finland // Demographic research. 10(6): 143-170.

Rossier C., L. Bernardi (2009). Social interaction effects on fertility: intentions and behaviors // European journal of population. 25: 467-485.

Santow G., M. Bracher (2001). Deferment of the first birth and fluctuating fertility in Sweden // European journal of population. 17: 343-363.

Schoen R., Y. Kim, C. Nathanson, J. Fields, N.M. Astone (1997). Why do Americans want children? // Population and development review. 23(2): 333-358.

Schoen R., N.M. Astone, Y.J. Kim, C.A. Nathanson, J.M. Fields (1999). Do fertility intentions affect fertility behavior? // Journal of marriage and family. 61(3): 790-799.

Settersten R.A.J., G.O. Hagestad (1996). What's the latest? Cultural age deadlines for family transitions // Gerontologist. 36(2): 178-188.

Skirbekk V. (2008). Fertility trends by social status // Demographic research. 18(5): 145-180.

Sobotka T. (2004). Postponement of childbearing and low fertility in Europe. Amsterdam: Dutch university press.

Sobotka T., F.C. Billari, H.-P. Kohler (2010). The return of late childbearing in developed countries: causes, trends and implications. Vienna: Vienna institute of demography.

Sobotka T., V. Skirbekk, D. Philipov (2011). Economic recession and fertility in the developed world // Population and development review. 2: 267-306.

Spéder Z., B. Kapita'ny (2009). How are time-dependent childbearing intentions realized? Realization, postponement, abandonment, bringing forward // European journal of population. 25: 503-523.

Steele F., C. Kallis, H. Goldstein, H. Joshi (2005). The relationship between childbearing and transitions from marriage and cohabitation in Britain // Demography. 42(4): 647-673.

Steele F., H. Joshi, C. Kallis, H. Goldstein (2006). Changing compatibility of cohabitation and childbearing between young British women born in 1958 and 1970 // Population studies. 60(2): 137-152. 
Steenhof L., A.C. Liefbroe (2008). Intergenerational transmission of age at first birth in the Netherlands for birth cohorts between 1935 and 1984: Evidence from municipal registers // Population studies. 62: 69-84.

Steglich C., T.A.B. Snijders, M. Pearson (2010). Dynamic networks and behavior: separating selection from influence // Sociological methodology. 40: 29-393.

Stewart S.D. (2002). The effect of stepchildren on childbearing intentions and births // Demography. 39(1): 181-197.

Surkyn J., R. Lesthaeghe (2004). Value orientations and the second demographic transition (SDT) in northern, western and southern Europe: an update // Demographic research (Special collection 3).

Swartz T.T. (2009). Intergenerational family relations in adulthood: patterns, variations, and implications in the contemporary United States // Annual review of sociology. 35: 191-212.

Tazi-Preve I., D. Bichlbauer, A. Goujon (2004). Gender trouble and its impact on fertility intentions // Yearbook of population research in Finland. 40: 5-24.

Testa M.R. (2006). Childbearing preferences and family issues in Europe. Special Eurobarometer. 253/Wave 65.1-TNS Opinion \& Social.

Thomson E. (1997). Couple childbearing desires, intentions and births // Demography. 34: 343 354.

Thomson E. (2002). Motherhood, fatherhood and family values // Meaning and choice: value orientations and life course decisions / R. Lesthaeghe, ed. The Hague: NIDI/CBGS Publications No. 37: 251-272.

Thomson E., J.M. Hoem (1998). Couple childbearing plans and births in Sweden // Demography. 35: $315-322$.

Thomson E., E. McDonald, L.L. Bumpass (1990). Fertility desires and fertility: hers, his, and theirs // Demography. 27: 579-588.

Thornton A. (1977). Children and marital stability // Journal of marriage and family. 39: 531540.

Thornton A. (1978). Marital dissolution, remarriage, and childbearing // Demography. 15: 361380.

Thornton A. (1980). The influence of first generation fertility and economic status on second generation fertility // Population and environment. 3: 51-72.

Thornton A., D. Philipov (2009). Sweeping changes in marriage, cohabitation and childbearing in Central and Eastern Europe: new insights from the developmental idealism framework // European journal of population. 25(2): 123-156.

Toulemon L., M.R. Testa (2005). Fertility intentions and actual fertility: a complex relationship // Population \& societies. 415: 4.

Van Bavel J. (2010). Choice of study discipline and the postponement of motherhood in Europe: the impact of expected earnings, gender composition and family attitudes // Demography. 47: $439-458$.

Van de Kaa D.J. (1997). Options and sequences: Europe's demographic patterns // Journal of the Australian population association. 14: 1-29. 
Van Giersbergen N.P.A., J. De Beer (1997). Geboorteontwikkeling en consumentenvertrouwen: een econometrische analyse (Birth trends and consumer confidence: An econometric analysis) // Maandstatistiek van de Bevolking. 1997(11): 23-27.

Vikat A., J.M. Hoem, E. Thomson (1999). Stepfamily fertility in contemporary Sweden: the impact of childbearing before the current union // Population studies. 53: 211-225.

Vikat A., Z. Spéder, G. Beets, F.C. Billari, C. Bu“hler, A. Desesquelles et al. (2007). Generations and gender survey (GGS): towards a better understanding of relationships and processes in the life course // Demographic research. 17: 389-439.

Vitali A., F.C. Billari, A. Prskawetz, M.R. Testa (2009). Preference theory and low fertility: a comparative perspective // European journal of population. 25(4): 413-438.

Wachter K.W., R.A. Bulatao (2003). Offspring: Human fertility behavior in biodemographic perspective. National Research Council, Committee on Population, Division on Behavioral and Social Sciences and Education. Washington, DC: The National Academies press.

Waite L.J., L.A. Lillard (1991). Children and marital disruption // American journal of sociology. 96(4): 930-953.

Walker J.R. (1995). The Effect of public policies on recent Swedish fertility behavior // Journal of population economics. 8(3): 223-251.

Westoff C., N. Ryder (1977). The predictive validity of reproductive intentions // Demography. 4: 431-453.

Whittington L.A. (1993). State income tax policy and family size: fertility and the dependent exemption // Public finance quarterly. 21(4): 378-398.

Willis R.J.A. (1973). New approach to the economic theory of fertility behavior // Journal of political economy. 81(2): 14-64.

Winkler-Dworak M., L. Toulemon (2007). Gender differences in the transition to adulthood in France: is there convergence over the recent period? // European journal of population. 23(3): 273-314.

Wu Z. (1996). Childbearing in cohabitational relationships // Journal of marriage and family. 58: 281-292.

Wu Z., C.M. Schimmele (2005). Repartnering after first union disruption // Journal of marriage and family. 67: 27-36.

Zimmer B.G., J. Fulton (1980). Size of family, life chances, and reproductive behavior // Journal of marriage and family. 42: 657-670. 


\title{
FERTILITY IN ADVANCED SOCIETIES:
}

\section{A REVIEW OF RESEARCH}

\author{
NiCOlETTA BALbO, Francesco C. BILlari, MELINDA Mills
}

\begin{abstract}
This paper provides a review of fertility research in advanced societies, societies in which birth control is the default option. The central aim is to provide a comprehensive review that summarizes how contemporary research has explained ongoing and expected fertility changes across time and space (i.e., cross- and withincountry heterogeneity). A secondary aim is to provide an analytical synthesis of the core determinants of fertility, grouping them within the analytical level in which they operate. Determinants are positioned at the individual and/or couple level (micro-level), social relationships and social networks (meso-level); and, by cultural and institutional settings (macro-level). The focus is both on the quantum and on the tempo of fertility, with a particular focus on the postponement of childbearing. The review incorporates both theoretical and empirical contributions, with attention placed on empirically tested research and whether results support or falsify existing theoretical expectations. Attention is also devoted to causality and endogeneity issues. The paper concludes with an outline of the current challenges and opportunities for future research.
\end{abstract}

Key words: fertility tempo, postponement, fertility quantum, low fertility, determinants of fertility

Nicoletta Balbo (n.f.g.balbo@rug.nl), University of GRONINGEn, THE NETHERLANDS.

Francesco C. Billari, University OF OXFord, UK.

Melinda Mills, University of Groningen, The Netherlands.

\section{REFERENCES}

Aassve A., F.C. Billari, Z. Spéder (2006). Societal transition, policy changes and family formation: evidence from Hungary // European journal of population. 22(2): 127-152.

Aassve A., F.C. Billari, R. Piccarreta (2007). Strings of adulthood: a sequence analysis of young British women's work-family trajectories // European journal of population. 23(3-4): 369388.

Aassve A., A. Goisis, M. Sironi (2011). Happiness and childbearing across Europe // Social indicators research: $1-22$.

Adserà A. (2004). Changing fertility rates in developed countries. The impact of labor market institutions // Journal of population economics. 17: 17-43.

Adserà A. (2010). Where are the babies? Labor market conditions and fertility in Europe // European journal of population. 27(1): 1-32.

Adserà A. (2011). The interplay of economic uncertainty and education in explaining second births in Europe // Demographic research. 25(16): 513-544.

Agrillo C., C. Nelini (2008). Childfree by choice: a review // Journal of cultural geography. 25: 347-363.

Ahn N., P. Mira (2002). A note on the changing relationship between fertility and female employment rates in developed countries // Journal of population economics. 15: 667-682.

Ajzen I. (1991). The theory of planned behavior // Organizational behavior and human decision processes. 50(2): 179-211. 
Amuedo-Dorantes C., J. Kimmel (2005). The motherhood wage gap for women in the United States: the importance of college and fertility delay // Review of economics of the household. 3: $17-48$.

Andersson G., K. Hank, M. Rønsen, A. Vikat (2006a). Gendering family composition: sex preferences for children and childbearing behavior in the Nordic countries // Demography. 43(2): 255-267.

Andersson G., J.M. Hoem, A.Z. Duvander (2006b). Social differentials in speed-premium effects in childbearing in Sweden // Demographic research. 14(4): 51-70.

Anderton D.L., N.O. Tsuya, L.L. Bean, G.P. Mineau (1987). Intergenerational transmission of relative fertility and life course pattern // Demography. 24: 467-480.

Aparicio Diaz B., T. Fent, A. Prskawetz, L. Bernardi (2011). Transition to parenthood: the role of social interaction and endogenous networks // Demography. 48(2): 559-579.

Astone N.M., C.A. Nathanson, R. Schoen, Y.J. Kim (1999). Family demography, social theory, and investment in social capital // Population and development review. 25(1): 1-31.

Axinn W.G., M.E. Clarkberg, A. Thornton (1994). Family influences on family size preferences // Demography. 31: 65-79.

Bailey M.J. (2010). Momma's got the pill. How Anthony Comstock and Griswold v. Connecticut shaped US childbearing // American economic review. 100(1): 98-129.

Baizán P., A. Aassve, F.C. Billari (2003). Cohabitation, marriage, and first birth: the interrelationship of family formation events in Spain // European journal of population. 19(2): 147-169.

Baizán P., A. Aassve, F.C. Billari (2004). The interrelations between cohabitation, marriage and first birth in Germany and Sweden // Population and environment. 25(6): 531-561.

Balbo N., M. Mills (2011). Social capital and pressure in fertility decision-making: second and third births in France, Germany and Bulgaria // Population studies. 65(3): 335-351.

Barber J.S. (2000). Intergenerational influences on the entry into parenthood: Mothers' preferences for family and non-family behavior // Social forces. 79: 319-348.

Barber J.S. (2001). The intergenerational transmission of age at first birth among married and unmarried men and women // Social science research. 30: 219-247.

Becker G.S. (1960). An economic analysis of fertility // Demographic and economic change in developed countries / G.S. Becker, ed. Princeton: Princeton university press: 209-231.

Becker G.S., H.G. Lewis (1973). On the interaction between the quantity and quality of children // Journal of political economy. 81(2): 279-288.

Becker G.S., K.M. Murphy, R. Tamura (1990). Human capital, fertility, and economic growth // Journal of political economy. 98(5): 12-37.

Begall K., M. Mills (2011). The impact of perceived work control, job strain and work-family conflict on fertility intentions: a European comparison // European journal of population. 27(4): 433-456.

Begall K., M.C. Mills (2012). The influence of educational field, occupation, and occupational sex segregation on fertility in the Netherlands // European sociological review. doi:10.1093/esr/jcs051.

Behrman J.R., M.R. Rosenzweig (2002). Does increasing women's schooling raise the schooling of the next generation? // American economic review. 92(1): 323-334. 
Benjamin K. (2001). Men, women, and low fertility: analysis across time and country. Unpublished working paper: University of North Carolina.

Berent J. (1953). Relationship between family sizes of the successive generations // Milbank memorial fund quarterly bulletin. 31: 39-50.

Bernardi L. (2003). Channels of social influence on reproduction // Population research and policy review. 22: 527-555.

Bernardi L., R. White (2009). Close kin influences on fertility behaviour // Family, kinship and state in contemporary Europe / P. Heady, M. Kohli, eds. Perspectives on theory and policy. Vol.3. Frankfurt: Campus.

Bernardi L., S. Keim, H. von der Lippe (2007). Social influences on fertility: a comparative mixed methods study in eastern and western Germany // Journal of mixed methods research. 1: $23-47$.

Bernhardt E., F. Goldscheider (2006). Gender equality, parenthood attitudes, and first births in Sweden // Vienna yearbook of population research, 2006: 19-39.

Berrington A. (2004). Perpetual postponers? Women's, men's and couple's fertility intentions and subsequent fertility behavior // Population trends. 117: 9-19.

Billari F.C. (2001a). A log-logistic regression model for a transition rate with a starting threshold // Population studies. 55(1): 15-24.

Billari F.C. (2001b). A sickle transition rate model with starting threshold // Statistical methods and applications. 10: 139-155.

Billari F.C. (2004). Becoming an adult in Europe: A macro(/micro)-demographic perspective // Demographic research. 3(2): 13-44.

Billari F.C. (2009). The happiness commonality: fertility decision in low-fertility settings // How generations and gender shape demographic change / UNECE, ed. New York/Geneva: United Nations: 7-38.

Billari F.C., H.-P. Kohler (2004). Patterns of low and lowest-low fertility in Europe // Population studies. 58(2): 161-176.

Billari F.C., H.-P. Kohler, G. Andersson, H. Lundstro“m (2007). Approaching the limit: longterm trends in late and very late fertility // Population and development review. 33: 149-170.

Billari F.C., D. Philipov (2004). Education and the transition to motherhood: a comparative analysis of Western Europe // European demographic research paper. 3. Vienna Institute of demography.

Billari F.C., D. Philipov, M. Testa (2009). Attitudes, norms and perceived behavioural control: explaining fertility intentions in Bulgaria // European journal of population. 25(4): 439-465.

Billari F.C., A. Goisis, A.C. Liefbroer, R.A. Settersten, A. Aassve, G. Hagestad et al. (2011). Social age deadlines for the childbearing of women and men // Human reproduction. 26(3): $616-622$.

Billingsley S. (2010). The post-communist fertility puzzle // Population research and policy review. 29(2): 193-231.

Blossfeld H.-P., S. Drobnic (2001). Careers of couples in contemporary societies: a crossnational comparison of the transition from male breadwinner to dual earner families. Oxford: Oxford university press. 
Blossfeld H.-P., J. Huinink (1991). Human capital investments or norms of role transition? How women's schooling and career affect the process of family formation // American journal of sociology. 97: 143-168.

Blossfeld H.-P., E. Klijzing, M. Mills, K. Kurz (2005). Globalisation, uncertainty, and youth in society. London: Routledge.

Bongaarts J. (2001). Fertility and reproductive preferences in post-transitional societies // Population and development review. 27: 260-281.

Bongaarts J. (2002). The end of the fertility transition in the developed world // Population and development review. 28(3): 419-443.

Bongaarts J., G. Feeney (1998). On the quantum and tempo of fertility // Population and Development Review. 24: 271-291.

Bongaarts J., S. Watkins (1996). Social interactions and contemporary fertility transitions // Population and development review. 22(4): 639-682.

Bourdieu P. (1986). The forms of capital // Handbook of theory and research for the sociology of education / J.G. Richardson, ed. New York: Greenwood: 241-258.

Bramoullé Y., H. Djebbari, B. Fortin (2009). Identification of peer effects through social networks // Journal of econometrics. 150(1): 41-55.

Breen R. (1997). Risk, recommodification and stratification // Sociology. 31(3): 473-489.

Brien M.J., L.A. Lillard, L.J. Waite (1999). Interrelated family-building behaviors: Cohabitation, marriage, and nonmarital conception // Demography. 36(4): 535-551.

Bryant J. (2007). Theories of fertility decline and the evidence from development indicators // Population and development review. 33: 101-127.

Buber I., A. Prskawetz (2000). Fertility in second unions in Austria: findings from the Austrian FFS // Demographic research. 3(2).

Buchmann M.C., I. Kriesi (2011). Transition to adulthood in Europe // Annual review of sociology. 37: 481-503.

Bühler C., E. Fratczak (2007). Learning from others and receiving support: the impact of personal networks on fertility intentions in Poland // European societies. 9(3): 359-382.

Bühler C., D. Philipov (2005). Social capital related to fertility: theoretical foundations and empirical evidence from Bulgaria // Vienna yearbook of population research, 2005: 53-81.

Bumpass L., J. Sweet, A. Cherlin (1991). The role of cohabitation in declining rates of marriage // Demography. 53: 913-927.

Butler D. (2004). The fertility riddle // Nature. 432: 38-39.

Buttern T., W. Lutz (1990). Estimating fertility responses to policy measures in the German Democratic Republic // Population and development review. 16(3): 539-555.

Butz W.P., M.P. Ward (1979). The emergence of countercyclical U.S. fertility // The American economic review. 69(3): 318-328.

Caldwell J.C., T. Schindlmayr (2003). Explanations of the fertility crisis in modern societies: a search for commonalities // Population studies. 57(3): 241-263.

Caltabiano M. (2008). Has the fertility decline come to an end in the different regions of Italy? New insights from a cohort approach // Population. 63(1): 157-172. 
Castles F.G., M. Ferrera (1996). Home ownership and the welfare state: is Southern Europe different? // South European society \& politics. 1(2): 163-185.

Chesnais J.-C. (1996). Fertility, family, and social policy // Population and development review. 22(4): 729-739.

Christakis N.A., J.H. Fowler (2007). The spread of obesity in a large social network over 32 years // New England journal of medicine. 357(4): 370-379.

Cigno A., J. Ermisch (1989). A microeconomic analysis of the timing of first births // European economic review. 33: 737-760.

Cigno A., F.C. Rosati (1992). The effects of financial markets and social security on saving and fertility behaviour in Italy // Journal of population economics. 5(4): 319-341.

Cohen S.B., J.A. Sweet (1974). The impact of marital disruption and remarriage on fertility // Journal of marriage and family. 36: 87-96.

Cohen-Cole E., J.M. Fletcher (2008). Is obesity contagious? Social networks vs. environmental factors in the obesity epidemic // Journal of health economics. 27(5): 1382-1387.

Coleman J.S. (1988). Social capital in the creation of human capital // American journal of sociology. 94 (Supp): 95-120.

Cooke L.P. (2009). Gender equity and fertility in Italy and Spain // Journal of social policy. 38(1): 123-140.

Cooke L.P., J. Baxter (2010). "Families"' in international context: comparing institutional effects across western societies // Journal of marriage and family. 72(3): 516-536.

Corijn M., E. Klijzing (2001). Transitions to adulthood in Europe. Dordrecht: Kluwer.

Corijn M., A.C. Liefbroer, J. De Jong Gierveld (1996). It takes two to tango, doesn't it? The influence of couple characteristics on the timing of the birth of the first child // Journal of marriage and family. 58: 117-126.

Dalla Zuanna G. (2001). The banquet of Aeolus: a familistic interpretation of Italy's lowest low fertility // Demographic research. 4(5): 133-162.

De Mouzon J., V. Goossens, S. Bhattacharya et al. (2010). Assisted reproductive technology in Europe, 2006: results generated from European registers by ESHRE // Human reproduction. 25: $1851-1862$.

Del Boca D. (2002). The effect of child care on participation and fertility // Journal of population economics. 15(3): 549-573.

Dommermuth L., J.E. Klobas, T. Lappega ${ }^{\circ}$ rd (2009). Now or later? The theory of planned behavior and fertility intentions. Dondena working paper. Milan: Carlo F. Dondena Centre for research on social dynamics.

Duncan O.D., R. Freedman, J.M. Coble, D.P. Slesinger (1965). Marital fertility and size of family of orientation // Demography. 2: 508-515.

Easterlin R.A. (1961). The American baby boom in historical perspective // American economic review. 51: 869-911.

Easterlin R.A. (1968). Population, labor force, and long swings in economic growth: the American experience. New York: Columbia university press.

Easterlin R.A. (1969). Towards a socioeconomic theory of fertility: a survey of recent research on economic factors in American fertility // Fertility and family planning: a world view / S.J. 
Behrman, L. Corsa Jr., R. Freedman, eds. Ann Arbor: University of Michigan press: 127156.

Easterlin R.A. (1976). The conflict between aspirations and resources // Population and development review. 2(3): 417-425.

Entwisle B., R.R. Rindfuss, D.K. Guilkey, A. Chamratrithirong, S.R. Curran, Y. Sawangdee (1996). Community and contraceptive choice in rural Thailand: A case study of Nang Rong // Demography. 33: 1-11.

Ermisch J. (1999). Prices, parents, and young people's household formation // Journal of urban economics. 45(1): 47-71.

Esping-Andersen G. (1990). The three worlds of welfare capitalism. Oxford: Polity press.

Esping-Andersen G. (1999). Social foundations of postindustrial economies. Oxford: Oxford university press.

Esping-Andersen G. (2009). The incomplete revolution: adapting welfare states to women's new roles. Cambridge: Polity press.

Fernández R., A. Fogli (2006). Fertility: The role of culture and family experience // Journal of the European economic association. 4(2-3): 552-561.

Fernández R., A. Fogli. (2009). Culture: an empirical investigation of beliefs, work, and fertility // American economic journal: Macroeconomics. 1(1): 146-177.

Feyrer J., B. Sacerdote, A. Stern (2008). Will the stork return to Europe? Understanding fertility within developed nations // Journal of economic perspectives. Summer. 22(3): 3-22.

Flap H., B. Vo"lker (2004). Creation and returns of social capital: a new research program. London: Routledge.

Fletcher J.M. (2011). Peer influences on adolescent alcohol consumption: evidence using an instrumental variables/fixed effect approach // Journal of population economics. doi:10.1007/s00148-011-0365-9.

Fokkema T., H. de Valk, J. de Beer, C. van Duin (2008). The Netherlands: childbearing within the context of a "Poldermodel"' society // Demographic research. 19(21): 743-794.

Frejka T. (2008). Birth regulation in Europe. Completing the contraceptive revolution // Demographic research. 19: 73-84.

Frejka T., G.W. Jones, J.-P. Sardon (2010). East Asian childbearing patterns and policy developments // Population and development review. 36: 579-606.

Friedman D., M. Hechter, S. Kanazawa (1994). A theory of the value of children // Demography. 31: $375-401$.

Furstenberg F.F.Jr, J.A. Levine, J. Brooks-Gunn (1990). The children of teenage mothers: patterns of early childbearing in two generations // Family planning perspectives. 22: 54-61.

Galasso V., R. Gatti, P. Profeta (2009). Investing for the old age: pensions, children and savings // International tax and public finance. 16(4): 538-559.

Gauthier A. (2007). The impact of family policies on fertility in industrialized countries: a review of the literature // Population research and policy review. 26: 323-346.

Gauthier A., J. Hatzius (1997). Family benefits and fertility: an econometric analysis // Population studies. 51: 295-306. 
Gibson-Davis C.M., K. Edin, S. McLanahan (2005). High hopes but even higher expectations: the retreat from marriage among low-income couples // Journal of marriage and family. 67: 1301-1312.

Goldin C. (2006). The quiet revolution that transformed women's employment, education, and family // American economic review. 96(2): 1-21.

Goldscheider F.K., L.J. Waite (1986). Sex differences in the entry into marriage // American journal of sociology. 92: 91-109.

Goldstein J., W. Lutz, M.R. Testa (2003). The emergence of sub-replacement family size ideals in Europe // Population research and policy review. 22(5): 479-496.

Goldstein J.R., T. Sobotka, A. Jasilioniene (2009). The end of lowest-low fertility? // Population and development review. 35(4): 663-700.

Granovetter M. (1973). The strength of weak ties // American journal of sociology. 78(6): 13601380.

Gustafsson S.S. (2001). Optimal age at motherhood. Theoretical and empirical considerations on postponement of maternity in Europe // Journal of population economics. 14(2): 225-247.

Gustafsson S.S. (2005). Having kids later. Economic analyses for industrialized countries // Review of economics of the household. 3(1): 5-16.

Hajnal J. (1965). European marriage patterns in perspective // Population in history / D.S. Glass, D.E.C. Eversley, eds. London: Edward Arnold: 101-143.

Hakim C. (2003). A new approach to explaining fertility patterns: Preference theory // Population and development review. 29(3): 349-374.

Hank K. (2001). Regional fertility differences in western Germany: an overview of the literature and recent descriptive findings // International journal of population geography. 7(4): 243257.

Hank K. (2002). Regional social contexts and individual fertility decisions: a multilevel analysis of first and second births in western Germany // European journal of population. 18(3): 281299.

Hank K., H.-P. Kohler (2000). Gender preferences for children in Europe: empirical results from 17 FFS countries // Demographic research. 2(1): 133-144.

Hank K., M. Kreyenfeld (2003). A multilevel analysis of child care and women's fertility decisions in western Germany // Journal of marriage and family. 65(3): 584-596.

Happel S.K., J.K. Hill, S.A. Low (1984). An economic analysis of the timing of childbirth // Population studies. 38: 299-311.

Harknett K.S., C.S. Hartnett (2011). Who lacks support and why? An examination of mothers' personal safety nets // Journal of marriage and family. 73(4): 861-875.

Harknett K., J. Knab (2007). More kin, less support: Multipartnered fertility and perceived support among mothers // Journal of marriage and family. 69(1): 237-253.

Harknett K., L. Hardman, I. Garfinkel, S.S. McLanahan (2001). The fragile families study: social policies and labor markets in seven cities // Children and youth services review. 23(6-7): $537-555$.

Heaton T.B., C.K. Jacobson, K. Holland (1999). Persistence and change in decisions to remain childless // Journal of marriage and family. 61(2): 531-539. 
Hendershot G.E. (1969). Familial satisfaction, birth order, and fertility values // Journal of marriage and family. 31: 27-33.

Hensvik L., P. Nilsson (2010). Business, buddies and babies. IFAU Working paper.

Heuveline P., J.M. Timberlake (2004). The role of cohabitation in family formation: the United States in comparative perspective // Journal of marriage and family. 66: 1214-1230.

Hirschman C. (1994). Why fertility changes // Annual review of sociology. 20: 203-233.

Hobcraft J., K. Kiernan (1995). Becoming a parent in Europe. Vol. 1 // European population conference / EAPS-IUSSP, ed. Milan: Franco Angeli: 27-65.

Hoem J.M. (1986). The impact of education on modern family-union initiation // European journal of population. 2: 113-133.

Hoem J.M. (2005). Why does Sweden have such high fertility? // Demographic research. 13(22): $559-572$.

Hoem J.M. (2008). Overview chapter 8: The impact of public policies on European fertility // Demographic research special collection. 7(19): 249-260.

Hoem B., J.M. Hoem (1997). Sweden's family policies and roller-coaster fertility. Jinko Mondai Kenkyu // Journal of population problems. 52: 1-22.

Hoem J.M., G. Neyer, G. Andersson (2006). Educational attainment and childlessness: the relationship between educational field, educational level, and childlessness among Swedish women born in 1955-59 // Demographic research 14: 331-380.

Hoffman L.W., M.L. Hoffman (1973). The value of children to parents // Psychological perspectives on population / J.T. Fawcett, ed. New York: Basic Books: 19-76.

Hoffman L.W., J.D. Manis (1979). The value of children in the United States: a new approach to the study of fertility // Journal of marriage and family. 41(3): 583-596.

Horwitz S.M., L.V. Klerman, H.S. Kuo, J.F. Jekel (1991). Intergenerational transmission of school-age parenthood // Family planning perspectives. 23(168-172): 177.

Iacovou M., L.P. Tavares (2011). Yearning, learning, and conceding: reasons men and women change their childbearing intentions // Population and development review. 37(1): 89-123.

Jansen M.D., A.C. Liefbroer (2006). Couples' attitudes, childbirth and the division of labor // Journal of family issues. 27: 1487-1511.

Jefferies J., A. Berrington, I. Diamond (2000). Childbearing following marital dissolution in Britain // European journal of population. 16: 193-210.

Johnson, N. E., \& Stokes, C. S. (1976). Family size in successive generations: the effects of birth order, international change in lifestyle, and familial satisfaction // Demography. 13: 175-187.

Jokela M., M. Kivima“ki, M. Elovainio, L. Keltikangas-Ja“rvinen (2009). Personality and having children: a two-way relationship // Journal of personality and social psychology. 96(1): 218230.

Jones L.E., A. Schoonbroodt, M. Tertilt (2011). Fertility theories. Can they explain the negative fertility-income relationship? // Demography \& the economy / J.B. Shoven, ed. Chicago: University of Chicago Press: 43-100.

Joshi H. (2002). Production, reproduction and education: women, children and work in a British perspective // Population and development review. 28: 445-474. 
Kahn J.R., K.E. Anderson (1992). Intergenerational patterns of teenage fertility // Demography. 29: 39-57.

Kalwij A. (2010). The impact of family policy expenditure on fertility in western Europe // Demography. 47(2): 503-519.

Keim S., A. Kla“rner, L. Bernardi (2009). Qualifying social influence on fertility intentions: composition, structure, and meaning of fertility-relevant social networks // Current sociology. 57(6): 1-20.

Kertzer D.I., M.J. White, L. Bernardi, G. Gabrielli (2009). Italy's path to very low fertility: the adequacy of economic and second demographic transition theories // European journal of population. 25(1): 89-115.

Kneale D., H. Joshi (2008). Postponement and childlessness: evidence from two British cohorts // Demographic research. 19: 1935-1968.

Kögel T. (2004). Did the association between fertility and female employment within OECD countries really change its sign? // Journal of population economics. 17(45): 65.

Kohler H.-P. (1997). Learning in social networks and contraceptive choice // Demography. 34: 369-383.

Kohler H.-P. (2001). Fertility and social interaction. An economic perspective. Oxford: Oxford university press.

Kohler H.-P., I. Kohler (2002). Fertility decline in Russia in the early and mid 1990s: the role of economic uncertainty and labour market crises // European journal of population. 18(3): 233262.

Kohler H.P., J.L. Rodgers (2003). Education, fertility, and heritability: explaining a paradox // Offspring: Fertility behavior in biodemographic perspective / K.W. Wachter, R.A. Bulatao, eds. Washington, DC: National Academies press: 46-90.

Kohler H.P., J.L. Rodgers, K. Christensen (1999). Is fertility behavior in our genes? Findings from a danish twin study // Population and development review. 25: 253-288.

Kohler H.-P., J.R. Behrman, S.C. Watkins (2001). The density of social networks and fertility decisions: evidence from South Nyanza District, Kenya // Demography. 38(1): 43-58.

Kohler H.P., F.C. Billari, J.A. Ortega (2002a). The emergence of lowest-low fertility in Europe during the 1990s // Population and development review. 28: 641-681.

Kohler H.-P., J.L. Rodgers, K. Christensen (2002b). Between nurture and nature: the shifting determinants of female fertility in Danish twin cohorts 1870-1968 // Social biology. 49: 218248.

Kohler H.-P., J.R. Behrman, A. Skytthe (2005). Partner ? children = happiness? The effects of partnerships and fertility on well-being // Population and development review. 31(3): 407445.

Kravdal Ø. (1992). The emergence of a positive relation between education and third birth rates in Norway with supportive evidence from the United States // Population studies. 46(3): 459475.

Kravdal Ø. (1994). The importance of economic activity, economic potential and economic resources for the timing of firth birth in Norway // Population studies. 48: 249-267.

Kravdal Ø. (1996). How the local supply of day-care centers influences fertility in Norway: a parityspecific approach // Population research and policy review. 15(3): 201-218. 
Kravdal Ø., R.R. Rindfuss (2008). Changing relationships between education and fertility: a study of women and men born 1940 to 1964 // American sociological review. 73: 854-873.

Kreyenfeld M. (2010). Uncertainties in female employment careers and the postponement of parenthood in Germany // European sociological review. 26(3): 351-366.

Kulu H. (2005). Migration and fertility: competing hypotheses re-examined // European journal of population. 21(1): 51-87.

Kulu, H. (2011). Why do fertility levels vary between urban and rural areas? // Regional studies. $1-17$.

Kulu H., P.J. Boyle (2009). High fertility in city suburbs: compositional or contextual effects? // European journal of population. 25(2): 157-174.

Kulu H., A. Vikat (2007). Fertility differences by housing type: the effect of housing conditions or of selective moves? // Demographic research. 17(26): 775-802.

Kulu H., P. Boyle, G. Andersson (2009). High suburban fertility: evidence from four Northern European countries // Demographic research. 21(31): 915-944.

Kuziemko I. (2006). Is having babies contagious? Fertility peer effects between adult siblings. Princeton university (working paper).

Lappegard T. (2002). Education attainment and fertility pattern among Norwegian women. Documents 2002/18. Department of social statistics, Statistics Norway, Oslo.

Lappegard T., M. Rønsen (2005). The multifaceted impact of education on entry into motherhood // European journal of population. 21: 31-49.

Le Goff J.-M. (2002). Cohabiting unions in France and in West Germany. Transitions to first birth and first marriage // Demographic research. 7(18): 594-624.

Lee R., A. Mason (2010). Fertility, human capital, and economic growth over the demographic transition // European journal of population. 26(2): 159-182.

Leridon H. (2008). A new estimate of permanent sterility by age: Sterility defined as the inability to conceive // Population studies. 62(1): 15-24.

Lesthaeghe R. (1983). A century of demographic and cultural change in Western Europe: an exploration of underlying dimensions // Population and development review. 9(3): 411-435.

Lesthaeghe R. (2010). The unfolding story of the second demographic transition // Population and development review. 36(2): 211-251.

Lesthaeghe R., D. van de Kaa (1986). Twee demografische transities? (Two demographic transitions?) // Bevolking - Groei en krimp, mens en maatschappij / Lesthaeghe, van de Kaa, eds. Deventer: Van Loghum Slaterus: 9-24.

Liefbroer A.C. (2005). The impact of perceived costs and rewards of childbearing on entry into parenthood: evidence from a panel study // European journal of population. 21(4): 367-391.

Liefbroer A.C. (2009). Changes in family size intentions across young adulthood: a life-course perspective // European journal of population. 25(4): 363-386.

Liefbroer A.C., F.C. Billari (2010). Bringing norms back in: a theoretical and empirical discussion of their importance for understanding demographic behavior // Population, space and place. 16(4): 287-305.

Lillard L.A., J.L. Waite (1993). A joint model of marital childbearing and marital disruption // Demography. 30: 653-681. 
Lin N., K.S. Cook, R.S. Burt. (2001). Social capital: Theory and research. New Brunswick: Aldine Transaction.

Livi-Bacci M. (2001). Too few children and too much family // Daedalus. 130: 139-156.

Lutz W., B.C. O’Neill, S. Scherbov (2003). Europe's population at a turning point // Science. 299: 1991-1992.

Lyngstad T.H., A. Prskawetz (2010). Do siblings' fertility decisions influence each other? // Demography. 47(4): 923-934.

Macunovich D.J. (1996). Relative income and price of time: exploring their effects on US fertility and female labor force participation // Population and development review. 22: 223257.

Mandemakers J.J., P.A. Dykstra (2008). Discrepancies in parent's and adult child's reports of support and contact // Journal of marriage and family. 70(2): 495-506.

Manlove J. (1997). Early motherhood in an intergenerational perspective: the experiences of a British cohort // Journal of marriage and family. 59: 263-297.

Manski C.F. (1993). Identification of endogenous social effects: the reflection problem // The review of economic studies. 60(3): 531-542.

Manski C.F. (1995). Identification problems in social sciences. New York: Harvard university press.

Manski C.F., J. Mayshar (2003). Private incentives and social interactions: Fertility puzzles in Israel // Journal of the European economic association. 1(1): 181-211.

Manuelli R.E., A. Seshadri (2009). Explaining international fertility differences // Quarterly journal of economics. 124(2): 771-807.

Margolis R., M. Myrskylä (2011). A global perspective on happiness and fertility // Population and development review. 37(1): 29-56.

Martin S.P. (2000). Diverging fertility among U.S. women who delay childbearing past age $30 / /$ Demography. 37: 523-533.

Martin J. (2004). The ultimate vote of confidence': Fertility rates and economic conditions in Australia, 1976-2000 // Australian social policy 2002-2003. Canberra: Commonwealth of Australia: 31-54.

Martin-Garcia T., P. Baizan (2006). The impact of type of education and of educational enrolment on first births // European sociological review. 22: 259-275.

Matthews B. (1999). The gender system and fertility: An exploration of the hidden links // Canadian studies in population. 26(1): 21-38.

Mayer K.U. (2004). Whose lives? How history, societies, and institutions define and shape life courses // Research in human development. 1(3): 161-187.

McCrary J., H. Royer (2011). The effect of female education on fertility and infant health: evidence from school entry policies using exact date of birth // American economic review. 101(1): 158-195.

McDonald P. (2000a). Gender equity in theories of fertility transition // Population and development review. 26(3): 427-439.

McDonald P. (2000b). Gender equality, social institutions and the future of fertility // Journal of population research. 17: 1-16. 
McDonald P., R. Kippen (2009). Fertility in South Australia: an overview of trends and socioeconomic differences, 2009. Report to the Department of trade and economic development. Adelaide: Government of South Australia.

McLanahan S., J. Adams (1987). Parenthood and psychological well-being // Annual review of sociology. 13: 237-257.

Mencarini L., M.L. Tanturri (2006). High fertility or childlessness: micro-level determinants of reproductive behaviour in Italy // Population. 61(4): 389-416.

Meron M., I. Widmer (2002). Unemployment leads women to postpone the birth of their first child // Population. 57(2): 301-330.

Michael R.T., N.B. Tuma (1985). Entry into marriage and parenthood by young men and women: the influence of family background // Demography. 22: 515-544.

Micheli G.A. (2000). Kinship, family and social network: the anthropological embedment of fertility change in Southern Europe // Demographic research. 3(13).

Miller A.R. (2010). The effect of motherhood timing on career path // Journal of population economics. 24(3): 1071-1100.

Miller W.B. (2011). Comparing the TPB and the T-D-I-B framework // Vienna yearbook of population research. 9(1): 19-29.

Miller W.B., D.J. Pasta (1994). The psychology of child timing: a measurement instrument and a model // Journal of applied social psychology. 24: 218-250.

Miller Torr B.M., S.E. Short (2004). Second births and the second shift: a research note on gender equity and fertility // Population and development review. 30: 109-130.

Milligan K. (2005). Subsidizing the stork: new evidence on tax incentives and fertility // Review of economics and statistics. 87(3): 539-555.

Mills M. (2004). Stability and change: the structuration of partnership histories in Canada, the Netherlands and the Russian Federation // European journal of population. 20: 141-175.

Mills M. (2010). Gender roles, gender (in)equality and fertility: an empirical test of five gender equity indices // Canadian population studies. 37(3/4): 445-474.

Mills M., K. Begall (2010). The impact of gender preferences on third Births in Europe: a multilevel examination of men and women // Population studies. 64(1): 77-95.

Mills M., H.-P. Blossfeld (2005). Globalization, uncertainty and the early life course: a theoretical framework // Globalization, uncertainty and youth in society/ H.-P. Blossfeld, E. Klijzing, M. Mills, K. Kurz, eds. London/New York: Routledge advances in sociology serie: $1-24$.

Mills M., L. Mencarini, M.L. Tanturri, K. Begall (2008). Gender equity and fertility intentions in Italy and the Netherlands // Demographic research. 18(1): 1-26.

Mills M., R.R. Rindfuss, P. McDonald, E. te Velde (2011). Why do people postpone parenthood? Reasons and social policy incentives // Human reproduction update. 17(6): 848860.

Mishra V., I. Nielsen, R. Smyth (2010). On the relationship between female labour force participation and fertility in G7 countries: evidence from panel cointegration and Granger causality // Empirical economics. 38(2): 361-372. 
Montgomery M.R., J.B. Casterline (1996). Social influence, social learning, and new models of fertility // Fertility in the United States: new patterns, new theories / J. Casterline, R. Lee, K. Foote, eds.: 87-99.

Morgan S.P., C.A. Bachrach (2011). Is the theory of planned behaviour an appropriate model for human fertility? // Vienna yearbook of population research. 9(1): 11-18.

Morgan S.P., H. Rackin (2010). The correspondence between fertility intentions and behavior in the United States // Population and development review. 36(1): 91-118.

Morgan S.P., M.G. Taylor (2006). Low fertility at the turn of the twenty-first century // Annual review of sociology. 32: 375-399.

Murphy M. (1993). The contraceptive pill and women's employment as factors in fertility change in Britain 1963-1980: a challenge to the conventional view // Population studies. 47(2): 221-243.

Murphy M., D. Wang (2001). Family-level continuities in childbearing in low-fertility societies // European journal of population. 17: 75-96.

Myers S.M. (1997). Marital uncertainty and childbearing // Social forces. 75: 1271-1289.

Myrskylä M., H.-P. Kohler, F.C. Billari (2009). Advances in development reverse fertility declines // Nature. 460(7256): 741-743.

Nauck B. (2007). Value of children and the framing of fertility: results from a cross-cultural comparative survey in 10 societies // European sociological review. 23(5): 615-629.

Neels K. (2010). Temporal variation in unemployment rates and their association with tempo and quantum of fertility: some evidence for Belgium, France and the Netherlands. Paper presented at the Annual meeting of the Population association of America, Dallas, 17 April.

Neyer G. (2003). Family policies and low fertility in Western Europe. Rostock: Max Planck Institute for demographic research (MPIDR Working paper).

Neyer G., G. Andersson (2008). Consequences of family policies on childbearing behavior: effects or artifacts? // Population and development review. 34: 699-724.

Neyer G.R., J.M. Hoem (2008). Education and permanent childlessness: Austria vs. Sweden; a research note // Demographic challenges for the 21st century: a state of the art in demography / J. Surkyn, P. Deboosere, J. Van Bavel, eds. Brussels: VUBPRESS.

Noguera C.S., K. Golsch, N. Stainhage (2003). Increasing uncertainty in the Spanish labour market and entry into parenthood // Genus. 58(1): 77-119.

O’Donoghue C., D. Meredith, E. O'Shea (2011). Postponing maternity in Ireland // Cambridge journal of economics. 35(1): 59-84.

OECD (2011). Doing better for families. OECD Publishing.

Olah L.S. (2003). Gendering fertility: Second births in Sweden and Hungary // Population research and policy review. 22: 171-200.

Oppenheimer V.K. (1988). A theory of marriage timing // American journal of sociology. 94: $563-591$.

Oppenheimer V.K. (1994). Women's rising employment and the future of the family in industrial societies // Population and development review. 20: 293-342.

Oppenheimer V.K. (2003). Cohabiting and marriage during young men's career-development process // Demography. 40: 127-149. 
Oppenheimer V.K., M. Kalmijn, N. Lim (1997). Men's career development and marriage timing during a period of rising inequality // Demography. 3: 311-330.

Örsal D.D.K., J.R. Goldstein (2010). The increasing importance of economic conditions for fertility. MPIDR Working Paper WP 2010-014. Rostock: Max Planck Institute for demographic research.

Pampel F.C. (2001). The institutional context of population change. Chicago: The University of Chicago press.

Pampel F.C., H.E. Peters (1995). The Easterlin effect // Annual review of sociology. 21: 163194.

Parr N. (2010). Satisfaction with life as an antecedent of fertility: partner ? happiness = children? // Demographic research. 22(21): 635-661.

Pfau-Effinger B. (1999). Change of family policies in the socio-cultural context of European societies // Family policies. Yearbook comparative social research (135-159) / A. Leira, ed. Stamford: JAI press.

Philipov D. (2002). Fertility in times of discontinuous societal change: the case of Central and Eastern Europe. MPIDR Working paper 2002-024. Rostock: Max Planck Institute for demographic research.

Philipov D. (2009). Fertility intentions and outcomes: The role of policies to close the gap // European journal of population. 25: 355-361.

Philipov D., Z. Speder, F.C. Billari (2006). Soon, later, or ever? The impact of anomie and social capital on fertility intentions in Bulgaria (2002) and Hungary (2001) // Population studies. 60(3): 289-308.

Pouwels B.J. (2011). Work, family, and happiness: essays on interdependencies within families, life events, and time allocation decisions. PhD dissertation. Utrecht: Utrecht university.

Prskawetz A., A. Vikat, D. Philipov, H. Engelhardt (2003). Pathways to stepfamily formation in Europe: results from the FFS // Demographic research. 8(5): 107-149.

Quesnel-Vallé A., S.P. Morgan (2003). Missing the target? Correspondence of fertility intentions and behavior in the U.S. // Population research and policy review. 22: 497-525.

Reher D.S. (1998). Family ties in western Europe: persistent contrasts // Population and development review. 24(2): 203-234.

Rendall M.S., R.A. Bahchieva (1998). An old-age security motive for fertility in the United States? // Population and development review. 24(2): 293-307.

Rijken A.J., A.C. Liefbroer (2009). The effects of relationship quality on fertility // European journal of population. 25: 27-44.

Rijken A.J., E. Thomson. (2011). Partners' relationship quality and childbearing // Social science research. 40(2): 485-497.

Rindfuss R., A. Vandenheuvel (1990). Cohabitation: a precursor to marriage or an alternative to being single? // Population and development review. 16(4): 703-726.

Rindfuss R.R., L. Bumpass, C. St. John (1980). Education and fertility: implications for the roles women occupy // American sociological review. 45: 431-447.

Rindfuss R.R., S.P. Morgan, K. Offutt (1996). Education and changing age pattern of American fertility: 1963-1989 // Demography. 33: 277-290. 
Rindfuss R.R., M.K. Choe, L.L. Bumpass, N.O. Tsuya (2004). Social networks and family change in Japan // American sociological review. 69: 838-861.

Rindfuss R.R., D.K. Guilkey, S.P. Morgan, O. Kravdal (2010). Child-care availability and fertility in Norway // Population and development review. 36(4): 725-748.

Rodgers J.L., H.P. Kohler, M. McGue, J.R. Behrman., I. Petersen, P. Bingley et al. (2008). Education and cognitive ability as direct, mediating, or spurious influences on female age at first birth: behaviour genetic models fit to Danish Twin data // American journal of sociology. 114(Supp): 202-232.

Rondinelli C., A. Aassve, F.C. Billari (2010). Women's wages and childbearing decisions: evidence from Italy // Demographic research. 22(19): 549-578.

Rosen M. (2004). Fertility and public policies-evidence from Norway and Finland // Demographic research. 10(6): 143-170.

Rossier C., L. Bernardi (2009). Social interaction effects on fertility: intentions and behaviors // European journal of population. 25: 467-485.

Santow G., M. Bracher (2001). Deferment of the first birth and fluctuating fertility in Sweden // European journal of population. 17: 343-363.

Schoen R., Y. Kim, C. Nathanson, J. Fields, N.M. Astone (1997). Why do Americans want children? // Population and development review. 23(2): 333-358.

Schoen R., N.M. Astone, Y.J. Kim, C.A. Nathanson, J.M. Fields (1999). Do fertility intentions affect fertility behavior? // Journal of marriage and family. 61(3): 790-799.

Settersten R.A.J., G.O. Hagestad (1996). What's the latest? Cultural age deadlines for family transitions // Gerontologist. 36(2): 178-188.

Skirbekk V. (2008). Fertility trends by social status // Demographic research. 18(5): 145-180.

Sobotka T. (2004). Postponement of childbearing and low fertility in Europe. Amsterdam: Dutch university press.

Sobotka T., F.C. Billari, H.-P. Kohler (2010). The return of late childbearing in developed countries: causes, trends and implications. Vienna: Vienna institute of demography.

Sobotka T., V. Skirbekk, D. Philipov (2011). Economic recession and fertility in the developed world // Population and development review. 2: 267-306.

Spéder Z., B. Kapita'ny (2009). How are time-dependent childbearing intentions realized? Realization, postponement, abandonment, bringing forward // European journal of population. 25: 503-523.

Steele F., C. Kallis, H. Goldstein, H. Joshi (2005). The relationship between childbearing and transitions from marriage and cohabitation in Britain // Demography. 42(4): 647-673.

Steele F., H. Joshi, C. Kallis, H. Goldstein (2006). Changing compatibility of cohabitation and childbearing between young British women born in 1958 and 1970 // Population studies. 60(2): 137-152.

Steenhof L., A.C. Liefbroe (2008). Intergenerational transmission of age at first birth in the Netherlands for birth cohorts between 1935 and 1984: Evidence from municipal registers // Population studies. 62: 69-84.

Steglich C., T.A.B. Snijders, M. Pearson (2010). Dynamic networks and behavior: separating selection from influence // Sociological methodology. 40: 29-393. 
Stewart S.D. (2002). The effect of stepchildren on childbearing intentions and births // Demography. 39(1): 181-197.

Surkyn J., R. Lesthaeghe (2004). Value orientations and the second demographic transition (SDT) in northern, western and southern Europe: an update // Demographic research (Special collection 3).

Swartz T.T. (2009). Intergenerational family relations in adulthood: patterns, variations, and implications in the contemporary United States // Annual review of sociology. 35: 191-212.

Tazi-Preve I., D. Bichlbauer, A. Goujon (2004). Gender trouble and its impact on fertility intentions // Yearbook of population research in Finland. 40: 5-24.

Testa M.R. (2006). Childbearing preferences and family issues in Europe. Special Eurobarometer. 253/Wave 65.1-TNS Opinion \& Social.

Thomson E. (1997). Couple childbearing desires, intentions and births // Demography. 34: 343354.

Thomson E. (2002). Motherhood, fatherhood and family values // Meaning and choice: value orientations and life course decisions / R. Lesthaeghe, ed. The Hague: NIDI/CBGS Publications No. 37: 251-272.

Thomson E., J.M. Hoem (1998). Couple childbearing plans and births in Sweden // Demography. 35: $315-322$.

Thomson E., E. McDonald, L.L. Bumpass (1990). Fertility desires and fertility: hers, his, and theirs // Demography. 27: 579-588.

Thornton A. (1977). Children and marital stability // Journal of marriage and family. 39: 531540.

Thornton A. (1978). Marital dissolution, remarriage, and childbearing // Demography. 15: 361380.

Thornton A. (1980). The influence of first generation fertility and economic status on second generation fertility // Population and environment. 3: 51-72.

Thornton A., D. Philipov (2009). Sweeping changes in marriage, cohabitation and childbearing in Central and Eastern Europe: new insights from the developmental idealism framework // European journal of population. 25(2): 123-156.

Toulemon L., M.R. Testa (2005). Fertility intentions and actual fertility: a complex relationship // Population \& societies. 415: 4.

Van Bavel J. (2010). Choice of study discipline and the postponement of motherhood in Europe: the impact of expected earnings, gender composition and family attitudes // Demography. 47: $439-458$.

Van de Kaa D.J. (1997). Options and sequences: Europe's demographic patterns // Journal of the Australian population association. 14: 1-29.

Van Giersbergen N.P.A., J. De Beer (1997). Geboorteontwikkeling en consumentenvertrouwen: een econometrische analyse (Birth trends and consumer confidence: An econometric analysis) // Maandstatistiek van de Bevolking. 1997(11): 23-27.

Vikat A., J.M. Hoem, E. Thomson (1999). Stepfamily fertility in contemporary Sweden: the impact of childbearing before the current union // Population studies. 53: 211-225. 
Vikat A., Z. Spéder, G. Beets, F.C. Billari, C. Bu“hler, A. Desesquelles et al. (2007). Generations and gender survey (GGS): towards a better understanding of relationships and processes in the life course // Demographic research. 17: 389-439.

Vitali A., F.C. Billari, A. Prskawetz, M.R. Testa (2009). Preference theory and low fertility: a comparative perspective // European journal of population. 25(4): 413-438.

Wachter K.W., R.A. Bulatao (2003). Offspring: Human fertility behavior in biodemographic perspective. National Research Council, Committee on Population, Division on Behavioral and Social Sciences and Education. Washington, DC: The National Academies press.

Waite L.J., L.A. Lillard (1991). Children and marital disruption // American journal of sociology. 96(4): 930-953.

Walker J.R. (1995). The Effect of public policies on recent Swedish fertility behavior // Journal of population economics. 8(3): 223-251.

Westoff C., N. Ryder (1977). The predictive validity of reproductive intentions // Demography. 4: 431-453.

Whittington L.A. (1993). State income tax policy and family size: fertility and the dependent exemption // Public finance quarterly. 21(4): 378-398.

Willis R.J.A. (1973). New approach to the economic theory of fertility behavior // Journal of political economy. 81(2): 14-64.

Winkler-Dworak M., L. Toulemon (2007). Gender differences in the transition to adulthood in France: is there convergence over the recent period? // European journal of population. 23(3): 273-314.

Wu Z. (1996). Childbearing in cohabitational relationships // Journal of marriage and family. 58: 281-292.

Wu Z., C.M. Schimmele (2005). Repartnering after first union disruption // Journal of marriage and family. 67: 27-36.

Zimmer B.G., J. Fulton (1980). Size of family, life chances, and reproductive behavior // Journal of marriage and family. 42: 657-670. 